\title{
In-situ Orientation and Crystal Growth Kinetics of P3HT in Drop Cast P3HT:PCBM Films
}

\author{
Abul F. Huq ${ }^{1 \dagger}$, Ali Ammar ${ }^{1}$, Abdullah M. Al-Enizi ${ }^{2}$ and Alamgir Karim ${ }^{1 *}$ \\ ${ }^{1}$ Department of Polymer Engineering, University of Akron, OH 44325 \\ ${ }^{2}$ Chemistry Department, Faculty of Science, King Saud University, PO Box 2455, Riyadh \\ 11451, Saudi Arabia \\ ${ }^{\dagger}$ Present address: Vision Ease, Ramsey, MN 55303
}

\begin{abstract}
Effect of casting solvents on drop cast thin films of conductive conjugated polymers is largely studied by characterizing post processed films. However, the results have often been inconclusive due to the complexity of the in-situ evolution of structures. In this research we implement in-situ grazing incidence wide angle x-ray scattering (GIWAXS) approach to extracting morphological evolution information during film formation in model Poly(3hexylthiophene) (P3HT): [6,6]-phenyl C61-butyric acid methyl ester (PCBM) blend films that have otherwise been widely studied. Casting solvents include chloroform, benzene and tetrahydrothiophene (THT), carefully selected for their relative solubilities of P3HT and PCBM. Individual casting solvent studies show that the casting solvents' solubility for P3HT and pure solvent boiling point, along with residual solvent content in the films have significant implications on final thin film morphology and crystallization of its constituent components. For example, the orientations of P3HT in P3HT:PCBM films, cast from different solvents, are largely affected by the individual solubilities of P3HT and PCBM, and substrate surface energy. On the other hand PCBM crystal growth from different PCBM solutions predominantly depends on the solubilities of PCBM in the solvents and boiling points of solvents. In this study we correlate and distinguish the drying behavior of the blend films with respect to the drying behavior of its constituent components. These results have important ramifications for controlling desired morphology for polymer electronics, such as organic photovoltaics (OPV), organic field effect transistor (OFET) and photo-detectors.
\end{abstract}

Keywords: P3HT, PCBM, GIWAXS, In-situ, Organic electronics, crystals dynamics

*E-mail: alamgir@uakron.edu

\section{INTRODUCTION}

Poly (3-hexylthiophene) (P3HT) is commonly utilized in different organic electronic applications, such as, organic field effect transistor $^{1-4}$ (OFET), photo detectors 5,6 , organic photovoltaics $^{7}$ (OPV), light emitting diode $^{6}$ (LED). Recently, as related to their application in organic photovoltaics (OPV), Dang et al. compiled a wide range of power conversion efficiencies of P3HT: [6,6]-phenyl C61-butyric acid methyl ester (PCBM). ${ }^{7}$ Large variations of reported electronic properties of $\mathrm{P} 3 \mathrm{HT}$ and $\mathrm{P} 3 \mathrm{HT}$ :PCBM based thin films is primarily due to lack of understanding of the correlation of different factors, such as post processing treatment, ${ }^{8}$ casting solvent, ${ }^{9,10}$ regioregularity, ${ }^{11,12}$ molecular weight and polydispersity ${ }^{13,14}$ of P3HT, active layer thickness, ${ }^{15}$ and underlying substrate properties ${ }^{1,16}$ to the morphology of the film. One of the key factors in optimizing P3HT orientation in neat films and P3HT:PCBM active layer morphology is the casting solvent. Furthermore, recently substantial effort has been dedicated to 
study the effect of mixed solvents and solvent additives on the morphology of such thin films. ${ }^{17,18}$ In various OPV studies it is found that variation of choice of casting solvents influences domain size, ${ }^{10}$ optical properties, ${ }^{19}$ photovoltaic parameters ${ }^{20}$ ( short circuit current, fill factor, power conversion efficiency, etc.), degree of P3HT crystallization, ${ }^{9}$ etc.

Characterization of structure and morphology of thin films of such OPV relevant materials is important for a good understanding of the fundamental structure-property-processing correlations that exist in such systems. X-ray is widely utilized in the forms of scattering, spectroscopy, reflectivity and diffraction to determine the morphology of polymer and polymer:nanoparticles thin films. ${ }^{21-23}$ Effects of polymer-substrate interaction and film thicknesses on the crystallization of such films are well studied by $\mathrm{X}$-ray techniques. ${ }^{23-28}$ In many such high impact research works, the authors have determined the crystal structure, its orientation, and preferential interfacial segregation of constituent components of blend films, etc. Such correlations of surface and interfacial aspects and the film morphology have direct bearings on their performance in organic electronic applications elucidated above.

While the effect of casting solvents on the above factors are recognized, the underlying scientific understanding associated with film morphology evolution during the film drying process of OPV films is not extensively studied. However, there are some grazing incidence $\mathrm{x}$ ray scattering (GIXS) studies on non-equilibrium and kinetic in situ drying behavior of conductive polymer:nanoparticle systems during film formation ${ }^{29,30}$ and dynamics of nanoparticles during the drying of colloidal droplet solutions ${ }^{31}$. For instance, an interesting dynamic correlation between the conductivity and the structural evolution during a P3HT droplet drying process is presented by Grodd et $a$. . by time resolved x-ray diffraction. ${ }^{32}$ They observed that the highest conductivity of P3HT is observed in the interconnected gel network. Even though further drying does not change the intensity of the characteristic P3HT structural peak, the conductivity of the film drops precipitously, most probably due to the loss of interconnectivity of the nano domains, present in the gel like structure. In this case therefore, the nonconductive solvent acts as a plasticizer or processing agent that promotes interconnectivity of the nanodomains. Moreover, there are in situ grazing incidence wide angle $\mathrm{X}$-ray study (GIWAXS) on solvent vapor annealing of P3HT:PCBM thin films. ${ }^{33}$ Therefore, with the increased accessibility of high energy synchrotron sources there is a scientific drive to better understand the transient behavior of thin films with custom built research setups on the beam line.

Even though the charge mobility of regioregular P3HT can vary by two orders of magnitude depending on the solvent used, ${ }^{34}$ the present understanding of effect of casting solvents on charge mobility in P3HT is rather confusing. Field effect mobility for P3HT is found to be substantially higher when the casting solvent is 1,2,4-trichlorobenzene as compared to that cast from chloroform. ${ }^{35}$ This is attributed to the higher boiling point of 1,2,4-trichlorobenzene (boiling point: $213^{\circ} \mathrm{C}^{36}$ ), that facilitates the crystallization of $\mathrm{P} 3 \mathrm{HT}$, as compared to those of chloroform (boiling point: $61.18^{\circ} \mathrm{C}^{36}$ ). Yang et al. conducted a more comprehensive study on field effect mobility as a function of solvents. ${ }^{4}$ In this study, field effect mobility as a function of solvent, $\mu_{\text {solvent, }}$, was rank ordered as $\mu_{\text {chloroform }}>\mu_{\text {tetrahydrofuran }}>>\mu_{\text {toluene }}>\mu_{\text {methylene chloride. Given }}$ that the solvent boiling points are methylene chloride $\left(39.75^{\circ} \mathrm{C}\right)<$ chloroform $\left(61.18^{\circ} \mathrm{C}\right)<$ 
tetrahydrofuran $\left(64.85^{\circ} \mathrm{C}\right)$, toluene $\left(110.63^{\circ} \mathrm{C}\right)$, one can conclude that there is no direct correlation between boiling point or associated vapor pressure and field effect mobility. While it is clear from the above discussion that it is difficult to correlate solvent properties and charge mobility in cast polymer films, there may be other more complex correlations in properties that can involve multiple cross-interacting parameters, such as substrate surface energy and solvent/solution wetting properties, etc. Furthermore, anisotropy in charge career mobility due to crystallization of P3HT makes degree of crystallization as well as crystal size and orientation of P3HT important factors in different electronic applications. ${ }^{22}$ Therefore, it is timely to understand the kinetics of P3HT and PCBM crystal growth in order to better appreciate device performance with the final morphology of thin films. Moreover, there is significant resemblance between the growth of thin film polymer crystals and that of small organic molecules as well as metals. ${ }^{37}$ Therefore, in many occasions it is a useful comparative candidate material for experimental studies of crystal growth. However, effects of casting solvents on crystal growth kinetics in polymers can be rather complex. Crystal growth rate for our OPV system largely depends on a number of variables including solubility of P3HT and PCBM, glass transition temperature of $\mathrm{P} 3 \mathrm{HT}$ and $\mathrm{PCBM}$ and suppression of glass transition temperature due to presence of solvent, substrate surface energy and roughness effects, as well as boiling point, volatility and partial vapor pressure of the solvent under study.

Of relevance to this study, P3HT and P3HT:PCBM films find applications in different organic electronic devices, such as, in organic field effect transistor (OFET), ${ }^{2-4}$ and photodetectors. ${ }^{5}$ In this paper, we focus on the crystallization structure evolution during the drying process of such drop cast films. Drop casting is widely used to make films on the order of nanometers to a few microns for studying different organic electronic devices. Unlike spin coating, drop casting allows for film formation under quiescent casting conditions. During the transition from solution to final film structure of drop cast organic electronic thin film, the morphological evolution is key to understanding and controlling the internal structures of drying films, e.g., by changing casting solvent(s). Therefore, in order to obtain a clearer and deeper understanding of the correlation between structure and performance of P3HT and P3HT:PCBM thin films, we need to understand the kinetics of structure evolution and crystallization of $\mathrm{P} 3 \mathrm{HT}$ and PCBM during the solvent evaporation process. With this goal in mind we examine the basic understanding of transient crystallization kinetics of drop cast active layer of P3HT:PCBM during film drying in relation to that of drying kinetics of the individual P3HT and PCBM components. Our in-situ study enables us to capture the kinetics of morphology evolution, frame by frame on the order of seconds, by grazing incidence wide angle X-ray scattering (GIWAXS) analysis of images obtained during the drying process of the drop cast films. In this way P3HT and PCBM and their blend crystal growth kinetics during the drying process of drop cast film is directly probed. This understanding has direct repercussion for controlling structure evolution in film-drying process during mass production of organic electronics, such as, ones produced by spraying of solvents, for example, inkjet printing. ${ }^{38}$

\section{EXPERIMENTAL}

Electronic grade, regioregular poly(3-hexylthiophene-2,5-diyl) (P3HT) (catalogue number \#4002-EE) was purchased from Rieke Metals, Inc., with molecular weight $\left(\mathrm{M}_{\mathrm{w}}\right)$ was $50 \mathrm{~K}-70 \mathrm{~K}$ with regioregularity of $91 \%$ to $94 \%$. Also, $99.5 \%$ pure Phenyl-C61-butyric acid 
methyl ester (PCBM) was purchased from nano-c, Inc. Three solvents, chloroform, benzene and tetrahydrothiophene (THT), were carefully selected for this research based on their relative solubilities of P3HT and PCBM. P3HT and PCBM are both fully soluble in chloroform, whereas benzene is only a relatively good solvent for PCBM and THT for P3HT. Solutions of 0.5\% P3HT, 0.5\% PCBM, and 0.5\%:0.5\% P3HT:PCBM by weight were prepared in each solvents. Polymer solutions were sonicated in a $50^{\circ} \mathrm{C}$ hot water bath followed by shaking in a vortex shaker. GIWAXS experiments were conducted at the D1 beam line of Cornell High Energy Synchrotron Source (CHESS). Samples were placed inside a chamber with two Kapton windows for x-ray to pass through from source to the sample to detector (see Figure 1(a)). The Kapton films were 30 micron thick each with a density of $1.43 \mathrm{gm} / \mathrm{cm}^{3}$. The wavelength of the $\mathrm{X}$-ray is $1.156 \AA$. Given this data, the transmittance of $\mathrm{x}$-ray is calculated to be $98 \%$.

The chamber was open to the air during experiment as shown in Figure 1(a). The same setup had previously been used for separate in situ solvent vapor annealing experiments. To save valuable GIWAXS time of setup change over, as well as to safeguard the sample from the turbulence of air ventilation, the same chamber was used. Our experimental process thus has a gas phase in equilibrium with a liquid phase or a solid phase in ambient condition. We note that the kapton windows produces two scattering rings in the GIWAXS image which do not interfere with the characteristic peaks of P3HT and PCBM (See Figure 1). Countdown (time) was started right after drop-casting the solution on the bare silicon substrate. However, it took some minimal time $(\sim 1 \mathrm{~min})$ to close the hatch of the $\mathrm{x}$-ray chamber and start the experiment. Our counting time began from the casting of solvents on the silicon wafers, and not from the first collected experimental data frame.

Experiments were conducted slightly above the critical angle of the film $\left(0.15^{\circ}\right)$ at the first waveguide resonance angle value. Thus we get the information on the through-film thickness range. During each in situ GIWAXS experimental run, a log file is generated, which contains different information such as, number of exposure taken per scan, exposure time, time stamp of data collection, sample alignment information, angle of incidence during experiment, any lateral position change of the sample during experiment, etc. For the particular set of reported experimental analysis in this paper, we are interested in the time stamp of each GIWAXS image and exposure time. The peak intensities are typically proportional to the sample exposure time, however, we cannot use the same exposure time to take every image since the detector can get over exposed as the peaks get stronger and stronger during the drying process.

Another issue to note is that these log files are relatively large since they contain the information of an entire set of in situ experiments, which may consist anywhere from 20 to 100 GIWAXS images in tiff format. To assist with this problem, the experimental log file data sorting was done by an " $\mathrm{R}$ " statistical programming code to extract the relevant information for data analysis and image sequencing (see code S1). Each tiff GIWAXS image can be considered as $1024 \times 1024$ matrix pixel values. Such data can be easily processed using a matlab code that enables us to take into account the scattering volume of the polymer exposed to the X-ray beam (see code S2). P3HT d-spacing and grain size was calculated from the (100) peak information (see Figure 1(b)) using Bragg's law and Scherrer equation, respectively. Full width half max of the (100) peak was calculated using the Voigt fit of OriginPro 9.0 software. 


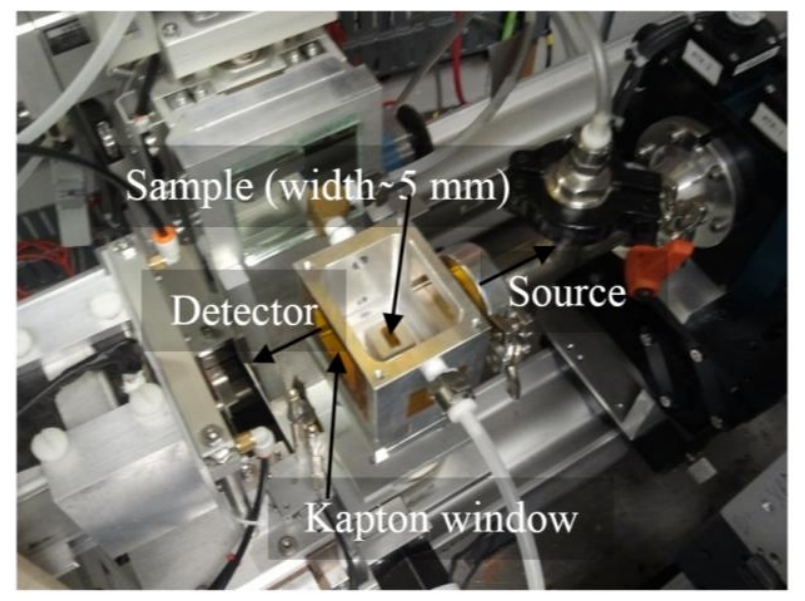

(a)

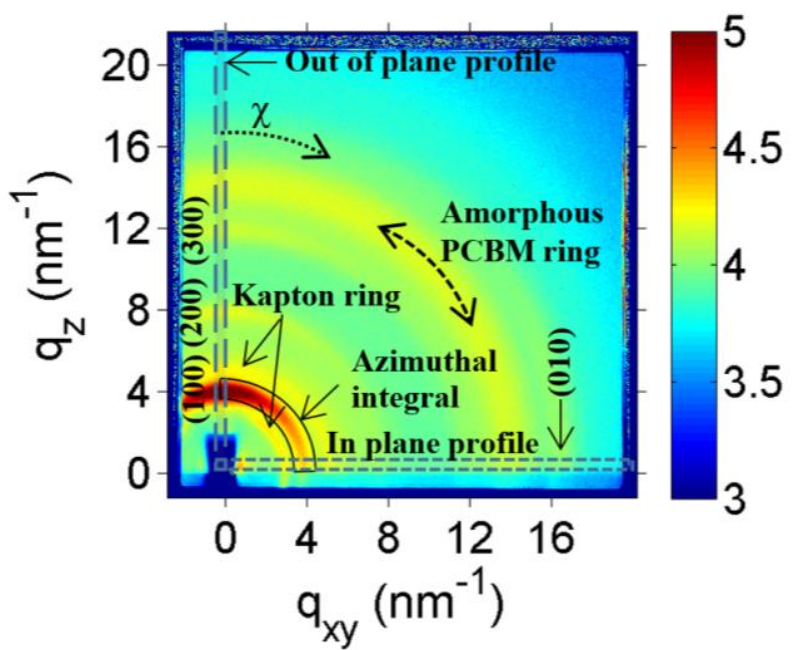

(b)

Figure 1. (a) GIWAXS experimental setup. Samples are placed on a mount of a chamber with two Kapton windows, placed between the source and detector. (b) A typical P3HT:PCBM scattering plot for a drop cast film. (100), (200) and (300) peaks appear due to preferential edge on orientation of P3HT. Different peaks, line cuts as well as the area where azimuthal integral average are taken is labeled. Azimuthal angle, $\chi$, direction is also presented by the dotted arrow. Out-of-plane profile as commonly referred to in P3HT:PCBM literature here refers to vertical slice, $\mathrm{q}_{\mathrm{z}}$ component of scattering profile.

Since the experiment was done inside a chamber with Kapton windows, we observe two scattering rings due to Kapton just below and above (100) P3HT peak. A representative GIWAXS image of a P3HT:PCBM thin film is presented in Figure 1b utilizing false "jet" color map of matlab. In this figure we illustrate different line cuts. Out of plane cut is very important since it provides the (100), (200) and (300) peak information, that typically comes from any edge-on orientation of P3HT. ${ }^{39,40}$ Position and intensity of (010) peak can be derived from the inplane line cut. The (010) peaks indicates $\pi-\pi$ stacking for face-on orientation of P3HT. For this particular film we can deduce that the P3HT is primarily oriented in an edge-on direction. On the other hand, the PCBM forms a halo (diffuse scattering ring), indicating presence of amorphous PCBM. Azimuthal integral averaging around (100) is necessary to picture the orientation of P3HT at different angles. In this consequence it is worth mentioning that such drop cast films has thickness of order of microns. Spin cast films are typically less than hundred to a few hundred nanometers. We observe that drop cast films have broader P3HT peaks as compared to that of spin cast films (see Figure S3). This means that P3HT structure is more isotropic in drop cast films than that of spin cast films. This is due to surface induced favorable edge-on orientation is diminished is film thickness increases. ${ }^{41}$ Here it should be noted that we poured enough sample solutions on the silicon wafer so that the whole wafer piece is flooded. Therefore, depending on the solution properties the amount of solution poured can differ. Moreover, due to coffee stain phenomenon there can be more materials at the edge of the wafer than in the middle of it. ${ }^{42,43}$ Thus, our results should be considered for qualitative comparison.

Film topography was scanned by a Bruker Corporation's "Dimension Icon" atomic force microscope (AFM) in standard tapping mode. Samples were further analyzed by scanning electron microscopy (SEM) utilizing Japan Electron Optics Laboratory (JEOL)-7401 field 
emission scanning electron microscope. Thermal gravimetric analysis (TGA) was conducted on the films by scraping the films, formed during the drying process of drop cast solutions under ambient condition for two hours, in order to determine the residual solvents in the films by TA instrument's Q50 model TGA machine with $10^{\circ} \mathrm{C}$ per minute ramping of temperature up to $700^{\circ} \mathrm{C}$. Particle and domain sizes were determined by Image $J$ software, developed at the National Institutes of Health (NIH).

\section{RESULTS AND DISCUSSION}

\section{Correlations of Film Formation with Solvent Properties}

Drying rates of the drop cast films of P3HT, PCBM and P3HT:PCBM blends, each cast from tetrahydrothiophene (THT), benzene $\left(\mathrm{C}_{6} \mathrm{H}_{6}\right)$ and chloroform $\left(\mathrm{CHCl}_{3}\right)$ were determined utilizing a 4-digital analytical balance. A constant initial solution volume of $70 \mathrm{mg} / \mathrm{cm}^{2}$ of substrate was deposited in each case, and the drying rate results presented in Figure 2. As shown in Figure 2a, casting solvent drying rate curves from THT exhibits three distinct regimes: constant drying rate period, decreasing drying rate period, and zero drying rate period. At "constant drying rate" period, the top surface of the solution is saturated with the solvent due to diffusion of solvents by the solvent gradient setup by the evaporation process. The rate of solution loss is controlled by evaporation rate, i.e., volatility of the solvent. As THT evaporation rate remains constant, the solution and the contacting substrate temperature more or less remains constant, since a constant amount of heat is withdrawn from the system as latent heat of THT evaporation. After that initial evaporation phase, when the sample is sufficiently dry, its surface cannot remain saturated by THT, as solvent diffusion from within the film cannot keep pace with the evaporation rate, i.e., evaporation becomes diffusion controlled. Consequently, the film temperature rises, and the drying rate also falls. This can be defined as "decreasing rate" period. Since the film thickness is in the order of microns, the decreasing rate period is expected to be short. Drying rate approaches zero towards the end of the decreasing rate period and eventually the "zero rate" period starts when the sample holds an equilibrium amount of solvent that evaporates extremely slowly. The zero drying rate is defined by the sharp and precipitous decline of drying rate profile from the decreasing drying period. Here it should be mentioned that drop cast thin films do not dry homogeneously everywhere. ${ }^{44}$ As the sample dries, the drying front is replenished from the central section of the solution by capillary flow (see Figure 2).

However, as the drying proceeds, the capillary flow cannot fully replenish the drying front, and the drying front recedes towards the center of the film. Therefore, in this case we expect some part of the sample to be evaporation controlled, while other part is diffusion controlled. This leads to inhomogeneous film formation (See Figure S4 for optical images of the films). We observed coffee-ring effects with the ring only towards the periphery of the wafer. Since we scanned at the flat locations in the central locations, we cannot comment on how the result may somehow affect by the coffee-ring effect. However, this potential effect is not expected to substantially impact the small centrally scanned measurements area in our studies. 

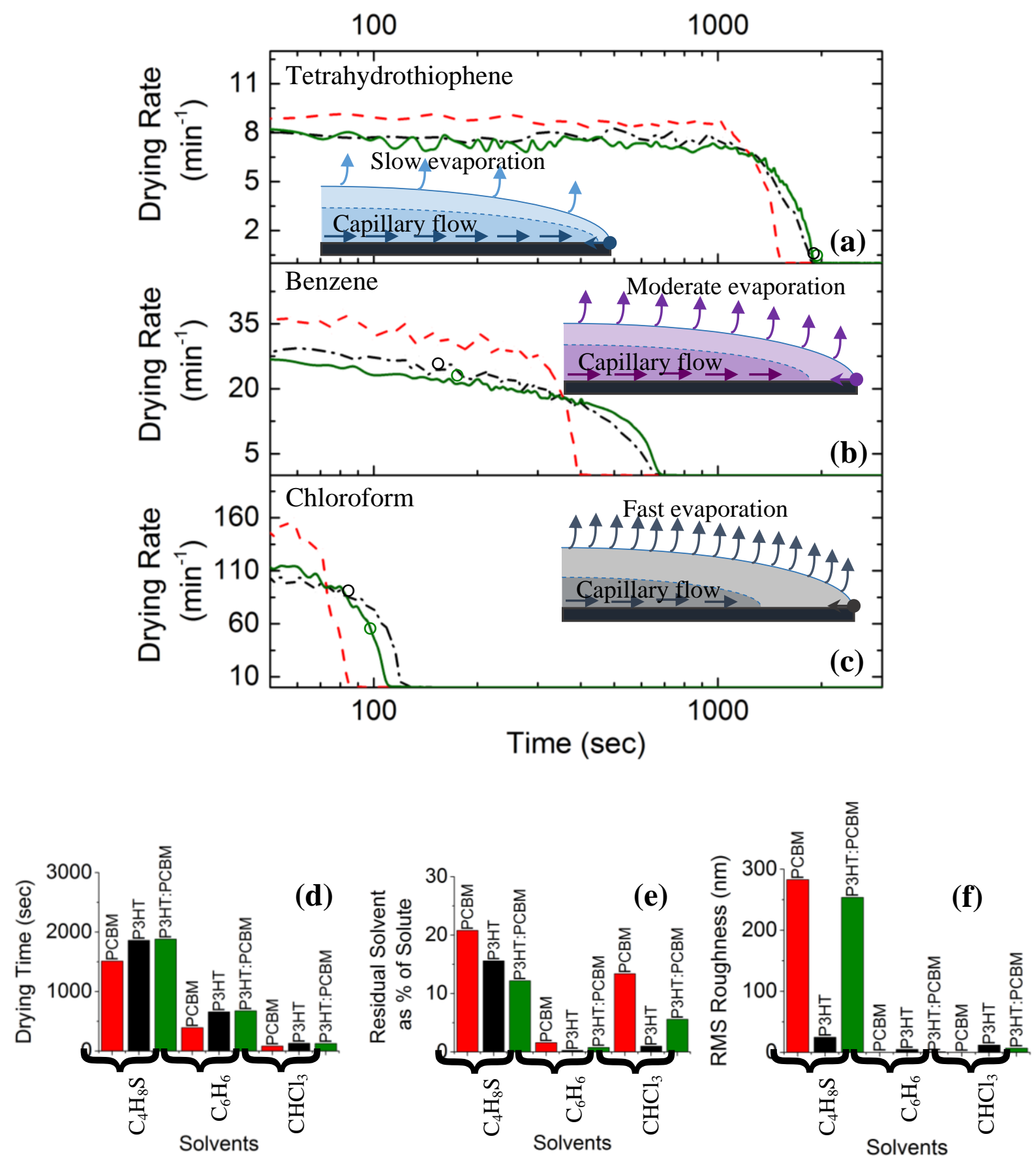

Figure 2. Drying behavior during P3HT:PCBM film formation, drop cast from different solvents. Red, black and green colors are the drying behaviors of PCBM, P3HT and P3HT:PCBM blends respectively. Drying rate is defined as evaporation of solvent $(S)$ per unit mass of solute (s) per minute for P3HT and PCBM drying (S/s.min). Note that in case of P3HT:PCBM blend drying rate is based on per unit mass of P3HT as the drying rate is more closely follow the drying rate of pristine P3HT in solution. Receding drying (direction is shown by arrow) front with time is shown in dashed line to the left of the drying curves. Approximate time of the appearance of first P3HT crystals are presented by circles. Black and green circles are for P3HT and P3HT:PCBM films respectively. (a), (b) and (c) are drying curves for THT, benzene and chloroform cast films respectively. (d) Presents drying time defined by when drying 
rate is reduced below $0.2 \mathrm{~s} / \mathrm{s} . \mathrm{min}$. (e) Bar-diagram of residual solvent contents in films cast from different solvents after two hours of drying in ambient condition. (f) RMS roughness of the films after two hours of drying of drop cast solutions.

We make several observations on the drying process. The drying front starts receding earlier at a faster rate in case of more volatile solvents as compared to that of less volatile solvents for all film systems (Figure $2(\mathrm{a}-\mathrm{c})$ ). This is simply because fast evaporation induces a fast receding of the drying front by out pacing capillary flow. The boiling points of THT, benzene and chloroform are $121.12^{\circ}, 80.09^{\circ}$, and $61.18^{\circ} \mathrm{C}$, respectively (also see Table 1 ).

Table 1. Relevant physical properties of solvents that influence the drying behavior of the films. Vapor pressure is calculated using Antoine type equation ${ }^{36}$.

\begin{tabular}{ccccc} 
& $\begin{array}{c}\text { Boiling point }^{36} \\
\left({ }^{\circ} \mathrm{C}\right)\end{array}$ & $\begin{array}{c}\text { Vapor } \\
\text { pressure } \\
\text { at } 20^{\circ} \mathrm{C} \\
(\mathrm{kPa})\end{array}$ & $\begin{array}{c}\text { P3HT } \\
\text { solubility } \\
\left(\mathrm{mg}^{46} \mathrm{ml}^{-1}\right)\end{array}$ & $\begin{array}{c}\text { PCBM } \\
\text { solubility }^{45} \\
\left(\mathrm{mg}^{\circ} \mathrm{ml}^{-1}\right)\end{array}$ \\
\hline THT & 121.12 & 1.864 & 37.6 & 6.7 \\
Benzene & 80.09 & 10.013 & 0.3 & 16.0 \\
Chloroform & 61.18 & 21.083 & 14.1 & 28.8
\end{tabular}

For the pure PCBM films, we note that the drying rate for all solvents (Figure 2(d)) is consistently higher during the initial "constant drying rate" phase, and its "drying time" as measured by abrupt decrease to zero drying rate is the shortest for all solvents. For the P3HT polymer and P3HT:PCBM blend films, these two solvent evaporation properties are roughly similar, and lower than PCBM. We can only hypothesize that rapid adsorption of the PCBM to the substrate, compared to the other two systems, allows the solvent on top to evaporate faster, as it is well known that nanoparticles can rapidly adsorb onto substrate surfaces while kinetics of polymer adsorption is mush slower.

From the above discussion it is also easily discernable why there is no sharp "constant drying rate" period and "decreasing rate" period in cases of benzene and chloroform as shown in Figure 2(b) and 2(c). Drying times for different films, dried from different solvents are presented in Figure 2(d) (Also see Table S5). Obviously it primarily depends on the boiling point of the solvent. However, the films retain some remaining solvent even after the drying period is over. This solvent content is typically denoted as the "residual solvent content". Intuitively, this residual solvent content should depend on the physical and chemical properties of the solvent and chemical interactions between the solvent and the solute. In order to determine the residual solvent content we conducted TGA on the samples (See Figure S6).

Figure 2(e) summarizes the residual solvent content in different films as a percentage of total solute contents in the films. We observe that the residual solvent content is largely depend on solubilities of the solutes and boiling points of the solvents presented in Table 1. As shown in Figure 2(e), films cast from THT can hold more solvent as compared to those cast from Benzene 
and chloroform because of the higher boiling point of THT. It is assumed that the surface adsorbed PCBM layer holds more solvent as compared to P3HT because of its particulate nature with side branching. There are more interstitial areas in randomly packed PCBM as compared to well-ordered semi-crystalline P3HT. Even though benzene has higher boiling point than chloroform, both P3HT and PCBM hold more residual chloroform than benzene. This can be due to higher affinity of both P3HT and PCBM towards chloroform than benzene.

In Figure 2(f) we summarize topographical root mean square (RMS) roughness of the dry films under study obtained through height scans of the AFM images. Films cast from THT have substantially higher roughness compared to those of benzene and chloroform. This is due to crystallization of PCBM in poor THT solvent ascribable to van der Waals force and enhanced crystallinity of PCBM. We observe enhanced crystallinity in poor solvent because during the drying process, the PCBM apparently phase-separates out from the solution at relatively high solvent content, creating nucleating sites for crystallization. Further slow drying of the solution (boiling point of THT is $121.12^{\circ} \mathrm{C}$ ) builds up large PCBM crystallites at the nucleating sites, creating a higher degree of RMS roughness.

\section{General Analysis Strategy of Time Dependent Structural Evolution of Films}

As discussed in the Experimental section, since upon drop casting, the solution starts drying immediately, GIWAXS images were taken as soon as possible after drying commenced. These images were utilized to construct time sequential contour plots, as measured for P3HT cast from Benzene, illustrated in Figure 3. In this article we present temporally varying vertical z-slice (varying $\mathrm{q}_{\mathrm{z}}$ component of the wavevector) and azimuthal integral average around (100) peak contour plots since these contain vital information on P3HT and PCBM via peak intensity, peak position and peak shifts as well as orientation change of P3HT crystals in the film with time and for different casting solvents.

In Table 2 we have summarized Hansen solubility parameters for the solvents and solutes used to better explain the interactions of polymer, nanoparticles and solvents and to understand and interpret the experimentally determined morphologies.

Table 2. Hansen solubility parameters of the solvents and solutes in study ${ }^{45}$

\begin{tabular}{lccc} 
& $\delta_{\mathrm{D}}\left(\mathrm{MPa}^{1 / 2}\right)$ & $\delta_{\mathrm{P}}\left(\mathrm{MPa}^{1 / 2}\right)$ & $\delta_{\mathrm{H}}\left(\mathrm{MPa}^{1 / 2}\right)$ \\
\cline { 2 - 4 } THT & 18.6 & 6.7 & 6.0 \\
Benzene & 18.4 & 0.0 & 2.0 \\
Chloroform & 17.8 & 3.1 & 5.7 \\
[60]PCBM (average) & 19.5 & 6.8 & 6.6 \\
P3HT (average) & 18.2 & 4.3 & 2.9
\end{tabular}




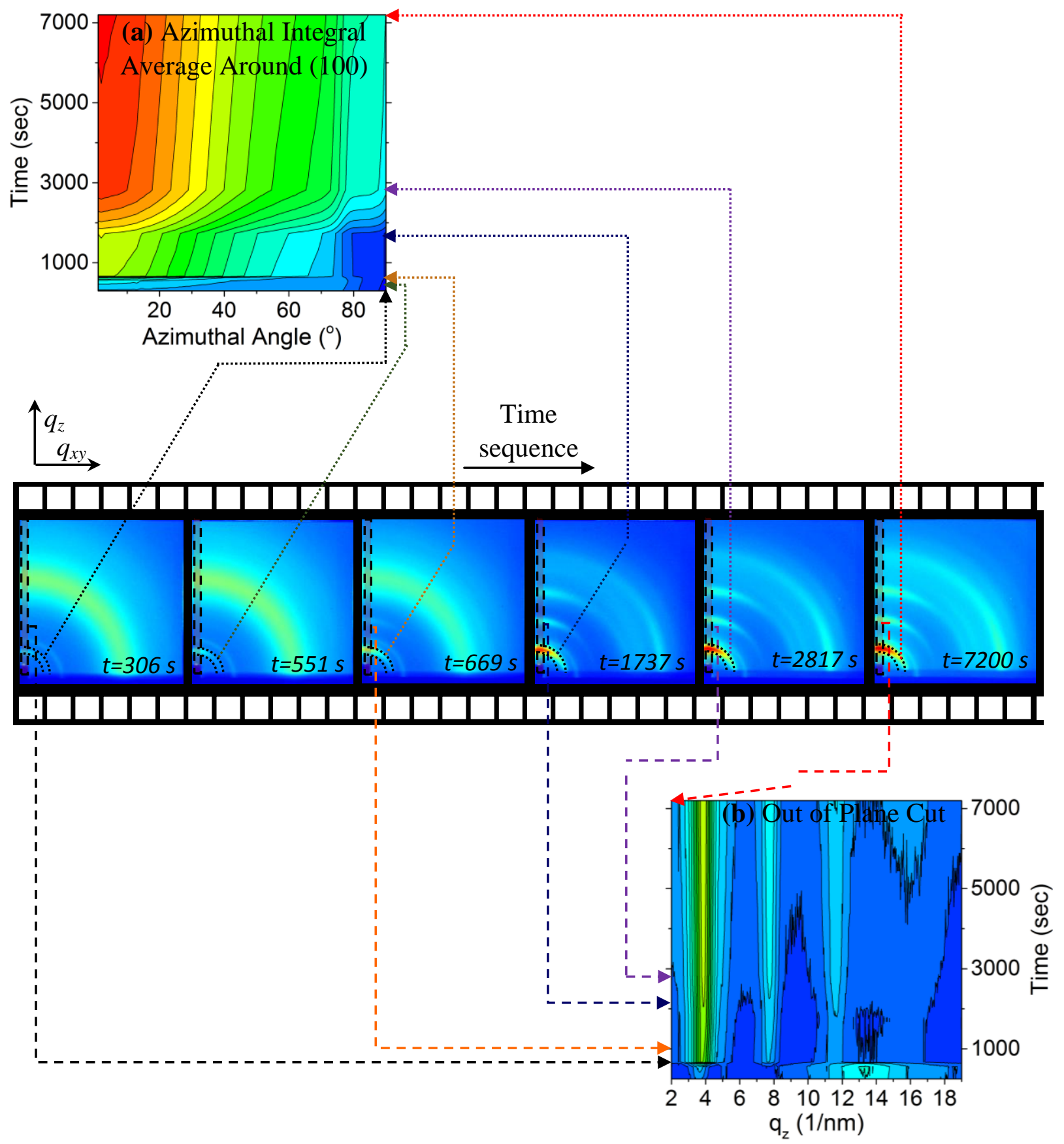

Figure 3. This figure explains the time sequential contour plot construction. In this particular case (a) azimuthal integral averages around (100) peak and (b) vertical slice (out-of-plane cut or $\mathrm{q}_{\mathrm{z}}$ component of wavevector) line cuts of GIWAXS images at different time frames are assembled to produce the construct.

Following the general description of analysis of the GIWAXS data, we now report on results on the time evolution of GIWAXS from the individual blend components of P3HT and PCBM, and in comparison to the blend of P3HT:PCBM during the drying process. 


\section{IN-SITU GIWAXS OF P3HT FILM DRYING}

We observed that the initial P3HT crystals appear in the decreasing drying rate periods. The first signature of P3HT crystal formation, as evinced by our in-situ GIWAXS measurements, indicate that they appeared at 74s, 153s and 1959s for chloroform, benzene and tetrahydrothiophene solvent cast films respectively. Clearly, the P3HT crystal induction time is dominated by the volatilities of the solvents.

The drying behavior of P3HT from chloroform in Figure 2(c) depicts that both constant and decreasing drying period ends within approximately $2 \mathrm{~min}$. We observe from the GIWAXS images presented in Figure 4(I): A-1 that the (100), (200) and (300) peaks appear right after the above drying period. The azimuthal integral average ( $\chi$ in polar co-ordinates) of GIWAXS intensity around the (100) peak depicts (see Figure 4(I): A-2) that the P3HT crystal orientation continues to reorganize with a gradient in isotropic distribution of intensity, i.e. crystal orientation bias more in the $\mathrm{z}$ direction within the film. The AFM image in Figure 4(I): A-3 demonstrates that such a drop cast film is not very smooth by AFM standards (RMS roughness $\sim 12 \mathrm{~nm}$ ), yet this is not so high for a micron thick film on a relative scale and maybe related to the P3HT lamellar thickness.

In the case of the P3HT film drying from benzene, from the drying curve data, it is observed that it takes much longer, around $11 \mathrm{~min}$. for constant and decreasing drying period to end. We observe that the P3HT characteristic peaks appear within about 7 min after drying starts. Therefore, the P3HT crystals must appear during the decreasing drying rate period. This can be attributed to the poor solubility of P3HT in benzene as its solution concentration exceeds a threshold value. Azimuthal integral average contour plots are constructed in such a way that radial vector parallel to out of plane cut represents $0^{\circ}$. From the azimuthal integral average contour plot (Figure 4(I): B-2), we observe that P3HT crystal orientation does not change much after the drying period is over, and its orientation is more spread compared to P3HT cast from chloroform show in Figure 4(I): A-2. This invariance in structure evolution can be attributed to not only poor solubility, but also a low mobility of P3HT due to the low residual solvent content present as indicated in Figure 2(e). From the AFM image inset of Figure 4(I): B-3, it is seen that the P3HT film forms small (crystalline) aggregates with a film RMS roughness $\sim 5 \mathrm{~nm}$.

When the casting solvent is THT, the P3HT crystal formation is substantially retarded due to good solubility of P3HT in THT and low evaporation rate of THT. In this particular case, the residual solvent content is as high as $15.6 \%$ and constant and decreasing rate period end at around $31 \mathrm{~min}$. Therefore, we observe an appearance of the first order peak, i.e., (100) peak after 33 mins (See Figure 4(I): C-1). We observe a halo at $q_{z}$ value of around $14 \mathrm{~nm}^{-1}$. This is due to the presence of THT solvent in the drying film. Likewise, Figure 4(I): C-2 depicts the azimuthal integral average around the first order P3HT peak as a function of time. P3HT crystals continue to grow for the entire $2 \mathrm{~h}$ of study. If we compare Figure 4(I): C-2 with 4(I): A-2 and 4(I): B-2, we observe that the crystal orientation in the present case of THT is less edge on and more face on as compared to those cast from chloroform and benzene. From SEM

and AFM images it can be seen that the domain structure of P3HT is larger than that of benzene. AFM image analysis of surface RMS roughness is found to be around $25 \mathrm{~nm}$. 


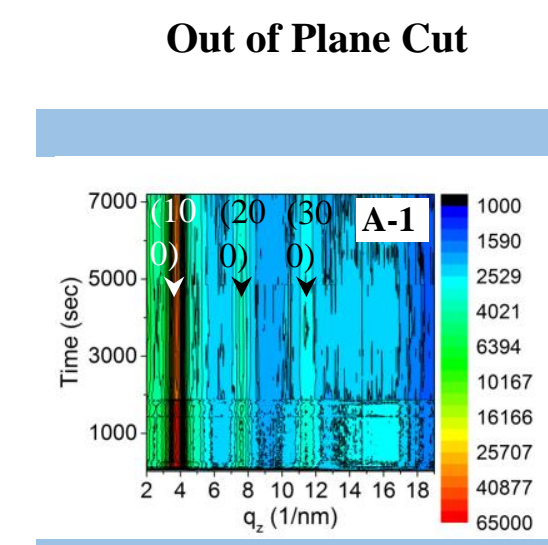
Azimuthal Integral Average
Around (100)
Chloroform

SEM and AFM after Vacuum Drying
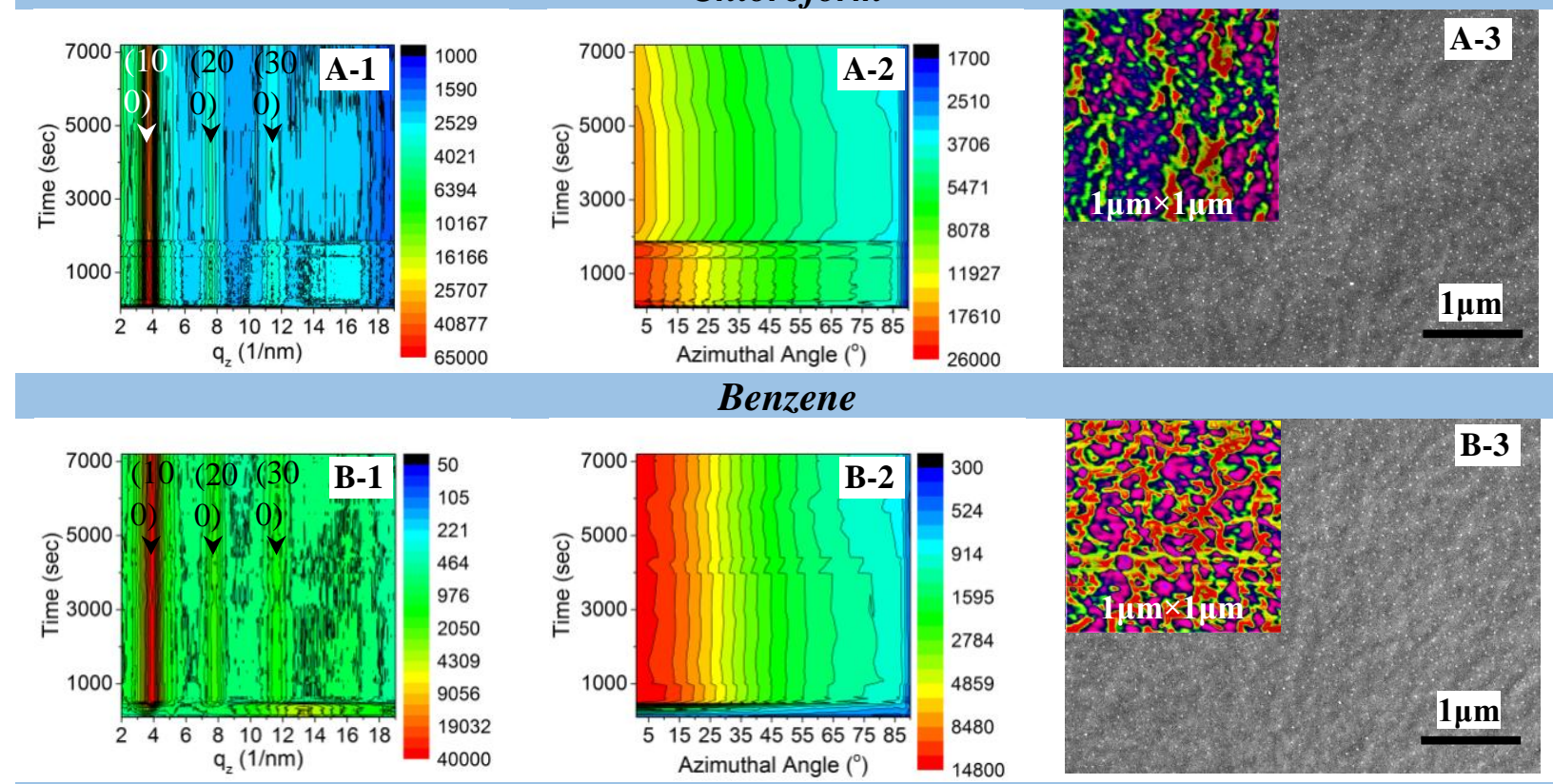

Benzene
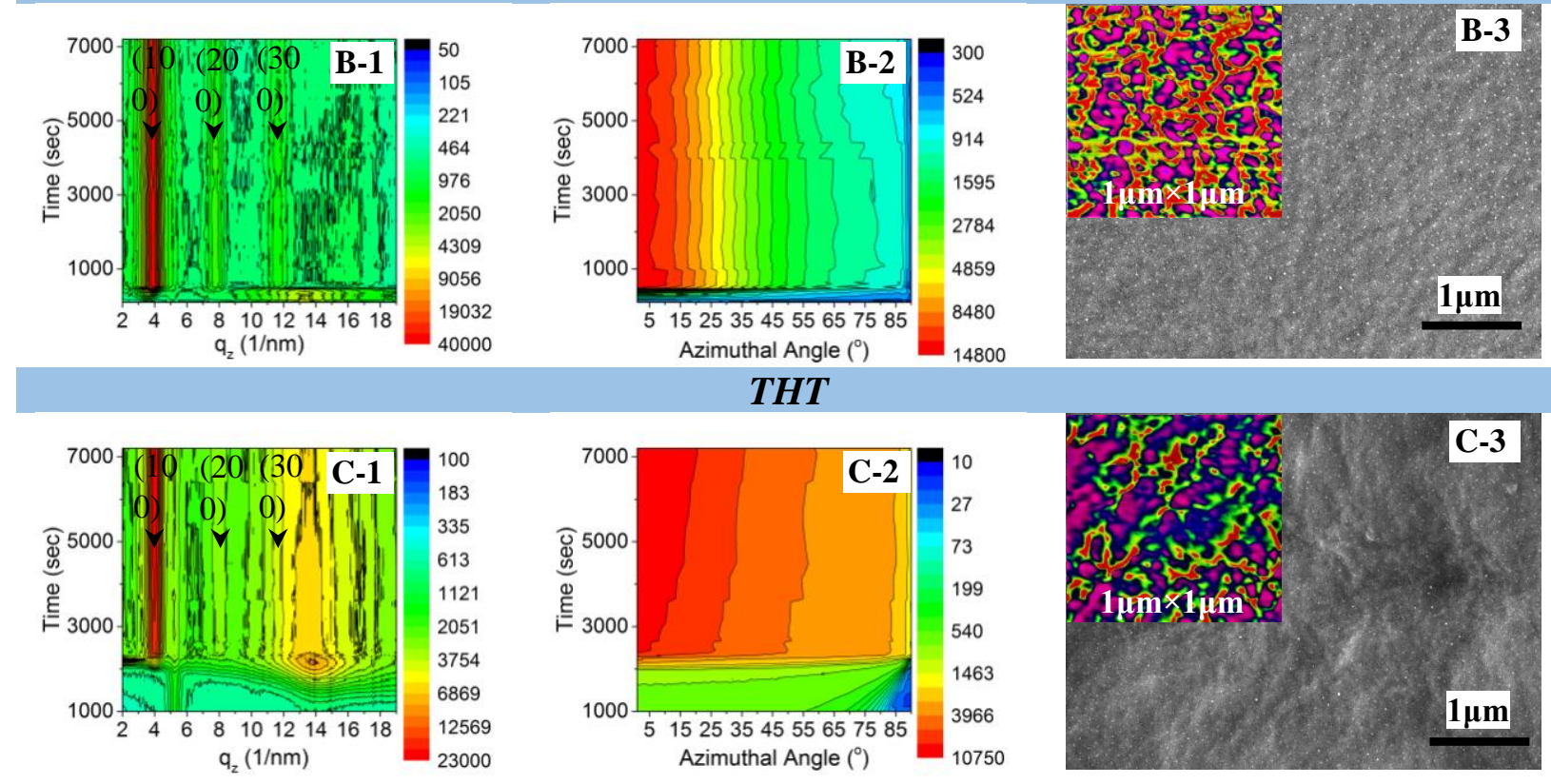

THT
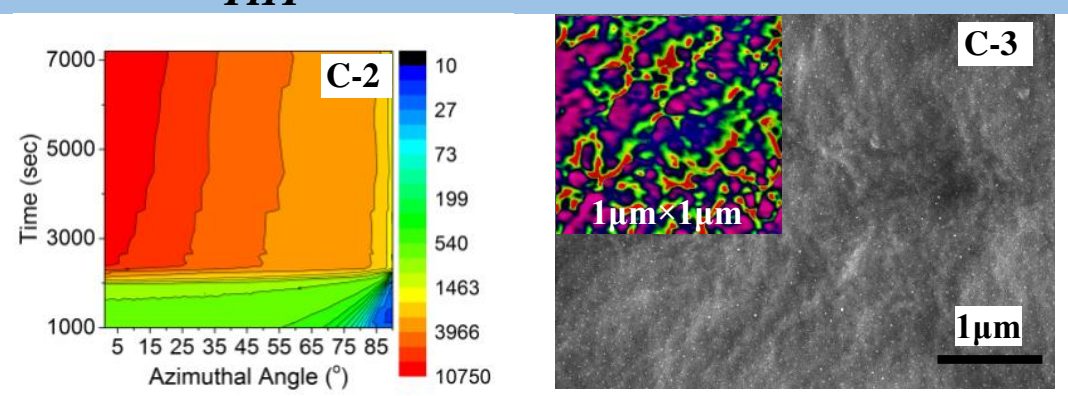

(I)
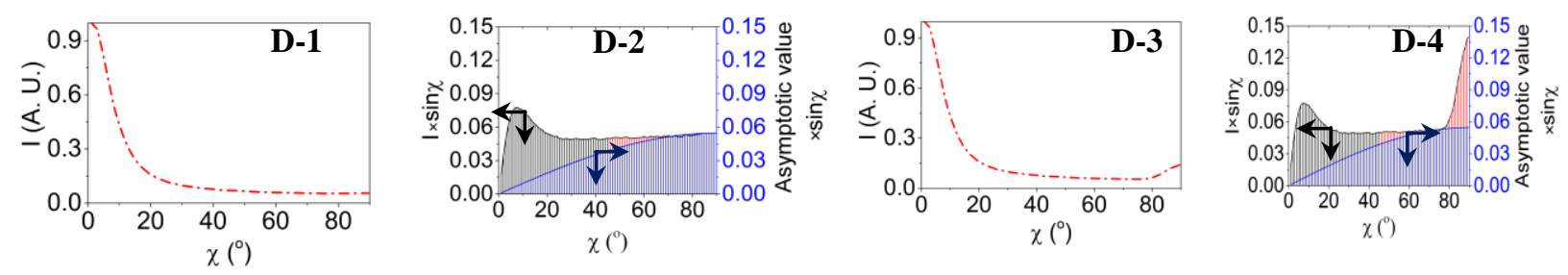

(II)

Figure 4. (I) P3HT drying frames for around two hours from different solvents. The images in the right column are SEM images with AFM phase images inset of the samples dried for two hours in ambient condition followed by three hours of vacuum drying. SEM scale bar is $1 \mu \mathrm{m}$. Results of first (A-1 to A-3), second (B-1 to B-3) and third (C-1 to C-3) rows of data presented are for films cast from chloroform, benzene, and THT, respectively. (II) Here we present two hypothetical examples where we explain the mathematical scheme to quantify the face-on, edge-on and isotropic fractions of the P3HT present in the film from an azimuthal integral average of scattered intensity, I $(\chi)$. D-1 illustrates the situation when there is an asymptotic decrease in intensity with azimuthal angle for edge-on orientation only, whereas, 
D-3 considers the situation where there is orientation in both edge-on and face-on directions. Figures (D2) and (D-4) provide quantitative analysis values of D-1 and D-3 respectively, to obtain edge on (black hatched area), isotropic (blue hatched area) and face on (red hatched area) components. In this process the entire intensity of azimuthal integral average curve product is multiplied by Sine of orientation angle, $\mathrm{I}(\chi)$ Sine $(\chi)$ in order to take into account for the tilt of the Ewald sphere. ${ }^{46}$ Isotropic fraction is obtained simply by multiplying the intensity values of the horizontal intensity values of D-1 and D-3 with sine of orientation angle, while Edge on and Face on components are defined as crystal grains with orientation angle, $\chi<45^{\circ}$ and angle, $\chi>45^{\circ}$, respectively.

P3HT crystal orientation fractions can be determined quantitatively from azimuthal integral average as shown in as shown in Figure 4(II). In this Figure we define edge-on as any crystal grain with orientation angle, $\chi<45^{\circ}$ and face-on as any crystal grain with orientation angle, $\chi>45^{\circ}$, and any other component of intensity (isotropic ring) is due to isotropic distribution of crystals. The relative portions of these three classes of crystals, edge-on, face-on and isotropic, cast from the 3 different solvents are presented as hatched areas in Figure 4(II): D-2. ${ }^{46}$ Black, red and blue hatched areas represent edge-on, face-on and isotropic components of crystal respectively. However, if there is preferential face-on structure, the azimuthal integral average intensity as a function of azimuthal angle would have an intensity profile like Figure 4(II): D-3. In that case the face-on crystal portion will increase, as shown in Figure 4(II): D-4. However all of our result resembles the azimuthal integral average profile presented in Figure 4(II): D-1 and presented in Figure 4(I) in the form of contour plots. From azimuthal integral averaging around (100) peak, presented in Figure 4(I) for P3HT cast from different solvents, we observe that there is an asymptotic decrease in intensity with angle. This implies that the orientation is predominantly edge-on and some isotropic and a minor amount of crystals is face on. We calculated edge-on, face-on and isotropic proportion by simple numerical trapezoidal approximation for area determination. The general trend is increase in edge on fraction with drying time (see Figure S8).

\section{IN-SITU GIWAXS OF PCBM FILM DRYING}

Cast PCBM solutions were dried separately from $0.5 \%$ solutions in chloroform, benzene and THT for $\sim 2 \mathrm{~h}$, and their overall 2D scattering pattern, and $\mathrm{q}_{\mathrm{z}}$ vertical component line cuts at $\sim 2 \mathrm{~h}$ are presented in Figure 5. The amorphous PCBM forms a halo, while sharp rings indicates randomly oriented PCBM crystals. Results presented in Figure 5 should be interpreted carefully since residual casting solvents form a superposed amorphous halo on the PCBM ring at around $q_{z}$ value of $14.4 \mathrm{~nm}^{-1}$. However, the residual casting solvent only forms a broad halo. Therefore, observations of a sharp ring must arise from PCBM crystals, albeit with random orientations. The scattering from any solvent as well as any amorphous PCBM results in a diffuse background on the sharp ring as explained in Figure 5(a). In addition, crystalline PCBM forms two rings at around $q_{x y}$ values of 6.4 and $7.5 \mathrm{~nm}^{-1}$ as shown in Figure 5(c). Here it is worth mentioning that the additional scattering rings arising around $q_{x y}$ values of 2.8 and 5.0 $\mathrm{nm}^{-1}$ are due to the Kapton window. Since residual solvent can contribute to the peak at 14.4

$\mathrm{nm}^{-1}$ that overlaps with that from PCBM, we chose to utilize the peaks at 7.5 and $6.4 \mathrm{~nm}^{-1}$ to determine the crystallinity of the PCBM phase, that are also clear of Kapton scattering peaks.

While crystal nucleation and growth mechanism is a thermodynamic process, crystallization kinetics play an important role in the case of our bulky PCBM and P3HT polymer system. In a highly mobile environment it is difficult to initiate stable crystal 
nucleating sites. On the other hand, when the mobility of the crystallizing phase is retarded, there may be several nucleating sites but the slower crystal growth rates. In Figure 5(b) we observe a sharp ring at $7.5 \mathrm{~nm}^{-1}$ indicating that a substantial portion of the PCBM is in randomly oriented crystalline form. In order to determine the sharpness and crystallinity of PCBM we utilize the full width half $\max$ (FWHM) of the ring at around $7.5 \mathrm{~nm}^{-1}$ of in plane line cut as a parameter.
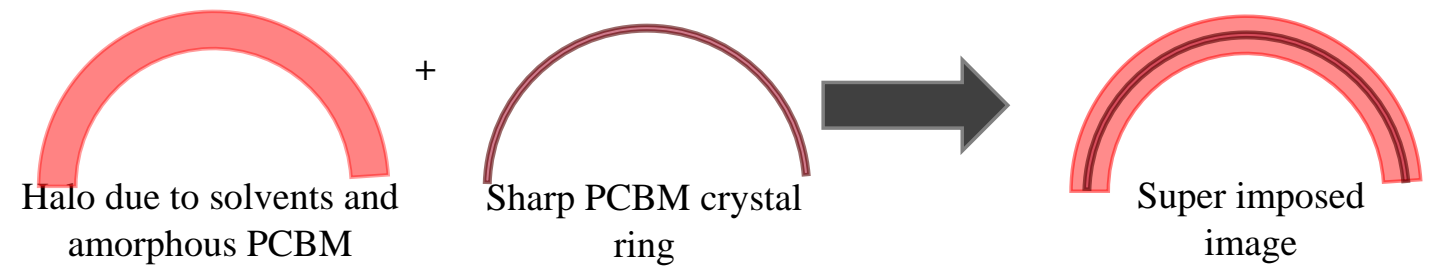

(a)
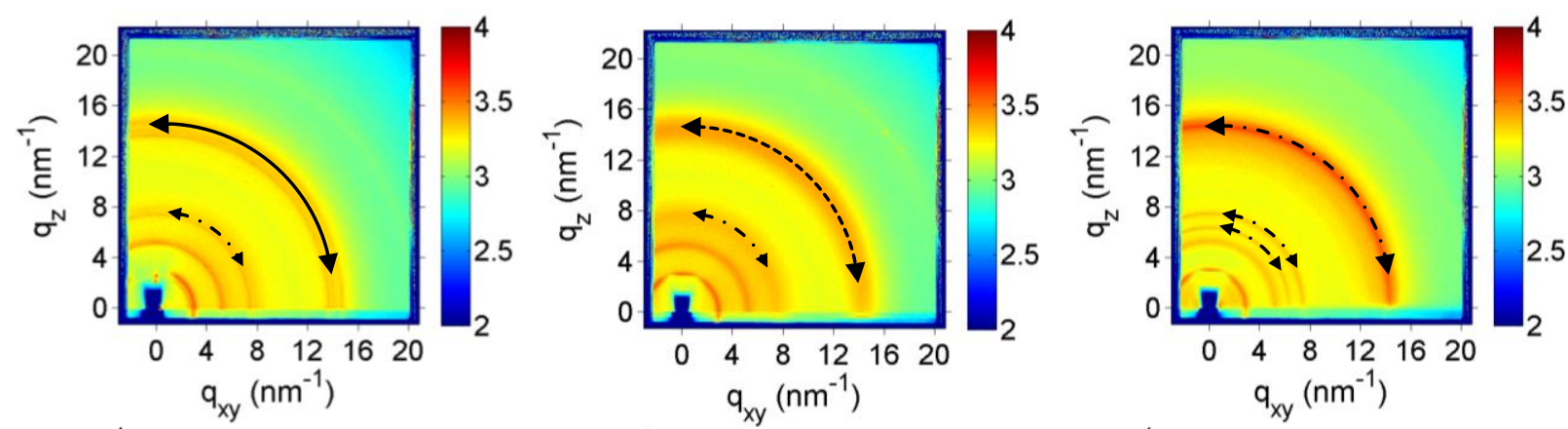

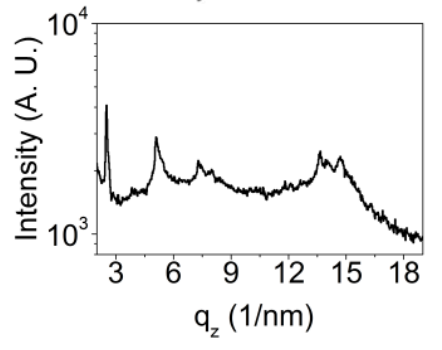

(b)

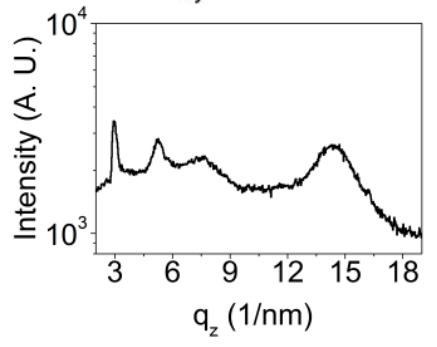

(c)

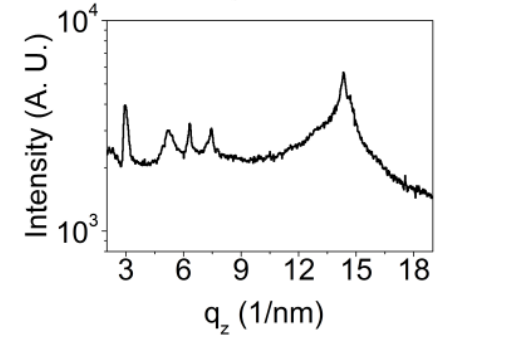

(d)

$0.5 \%$ PCBM, after $2 \mathrm{~h} 2 \mathrm{~min} 6 \mathrm{~s}$ of drop casting from chloroform

$0.5 \%$ PCBM, after $1 \mathrm{~h} 58 \mathrm{~min} 41 \mathrm{~s}$ of drop casting from benzene
$0.5 \%$ PCBM, after $1 \mathrm{~h} 59 \mathrm{~min} 27 \mathrm{~s}$ of drop casting from THT

Figure 5. (a) Superposition of amorphous halo and sharp PCBM crystal ring. Amorphous halo can be due to the contribution from residual solvent and amorphous PCBM. PCBM drying frames and vertical $\mathrm{q}_{\mathrm{z}}$ line cuts after around two hours of drying upon casting from different solvents, (b) chloroform, (c) benzene, and (d) THT.

In case of chloroform dried PCBM films, we observed a sharp peak at $7.5 \mathrm{~nm}^{-1}$ with FWHM $=0.45 \mathrm{~nm}^{-1}$ (Figure 5(b)). Therefore, we conclude that upon drying for around $2 \mathrm{~h}$ at ambient condition from chloroform, PCBM crystallites with no preferential orientation are formed. In the case of benzene cast PCBM films, Figure 5(c) shows a very weak and broad peak that appears at $\sim 7.5 \mathrm{~nm}^{-1}$ due to the presence of PCBM $\left(\right.$ FWHM=1.28 $\left.\mathrm{nm}^{-1}\right)$. If we compare the solubility parameters listed in table 2, we see that both benzene and PCBM have similar values of Hansen solubility parameters, which makes it a good solvent for PCBM. The 
residual benzene content in PCBM is only $1.6 \%$. We believe that in the constant drying rate period, PCBM did not form crystals since it was in a solution (liquidius) state rather than crystalline form. During the short decreasing rate period, it may form some crystals, but the crystal formation is impeded due to the low amount of residual solvent content (1.6\%) (glass transition temperature of PCBM, $T_{g}=131^{\circ} \mathrm{C}^{47}$ ) restricting its mobility. In the case of THT cast PCBM films (Figure 5(d)), since PCBM has poor solubility in THT, it is precipitated during the drying process and subsequently forms crystals. The rings at 6.4 and $7.5 \mathrm{~nm}^{-1}$ are typical signatures of the presence of randomly oriented crystals. Further, the sharpness of the peak at $14.4 \mathrm{~nm}^{-1}$ is due to PCBM crystals. This is further corroborated by the lower FWHM $\left(=0.34 \mathrm{~nm}^{-}\right.$ ${ }^{1}$ ) of the $7.5 \mathrm{~nm}^{-1}$ peak than the other two solvents. However, it is worth noting that the background halo at $14.4 \mathrm{~nm}^{-1}$ can be, in part, due to presence of high residual THT solvent after $2 \mathrm{~h}$.

The data presented so far was representative of film structure evolution and analysis after passage of a fixed time evolution from the start of the drying process. Next in Figure 6 we present time sequential contour plots derived from vertical slice of $\mathrm{q}_{\mathrm{z}}$ cuts of GIWAXS images of PCBM during the drying process for the solvents under study. In this figure we also present SEM and AFM images, taken after $2 \mathrm{~h}$ of drying in ambient condition followed by drying under vacuum for $3 \mathrm{~h}$. GIWAXS images show that the PCBM cast film forms a halo at the early stage of drying from chloroform (see Figure 6A-1). For the PCBM film, the constant rate and decreasing rate period of drying ends within a short time of less than $2 \mathrm{~min}$. However, the halo ring, observed at around $14.4 \mathrm{~nm}^{-1}$ becomes sharper towards the end of $2 \mathrm{~h}$ drying period indicating that even after drying, PCBM remains mobile and continues to reorganize due to presence of substantial residual chloroform content. From the corresponding AFM phase image we observe a very fine surface structure due to small PCBM aggregate formation.

By comparison, a time sequence drying plot of PCBM cast from benzene is presented in Figure 6A-2. Here we observe that PCBM forms an amorphous halo at around $14.4 \mathrm{~nm}^{-1}$ throughout the whole drying period. Therefore, we conclude that in this case due to lower residual solvent content in the PCBM film, the PCBM has a lower mobility and crystal formation is impeded. AFM phase image of Figure 6B-2 suggests that PCBM forms small aggregates. When the casting solvent is THT, we observe sharp peaks at 6.4 and 7.5 and 14.4 $\mathrm{nm}^{-1} q_{z}$ values after 28 min, i.e., immediately after constant and decreasing drying rate period. This implies that most of the PCBM present in the film forms a random crystal structure. From SEM and AFM height images we observe that a nanoporous structure of PCBM is formed. We believe that since THT is not a good solvent for PCBM, during the drying process in the solution, PCBM rich and lean phases form and phase inversion occurs in this process. ${ }^{48}$ Due to formation of such structure, the film roughness approaches $\sim 300 \mathrm{~nm}$ for the dried film. This type structure can be controlled by mixed good and poor casting solvents of PCBM. Such nanoporous structure of nanoparticles can be very interesting in different applications including organic photovoltaics. For instance, if we can infuse them with donor conjugated polymer for example with selective solvents, then we can get very well defined donor - acceptor interfacial boundary. We anticipate that this can have a positive impact on organic photovoltaics due to well-defined donor-acceptor interfaces for efficient exciton separation without recombination. 


\section{Chloroform}

Benzene

THT

\section{Out of Plane Cuts (Semi-log plot)}
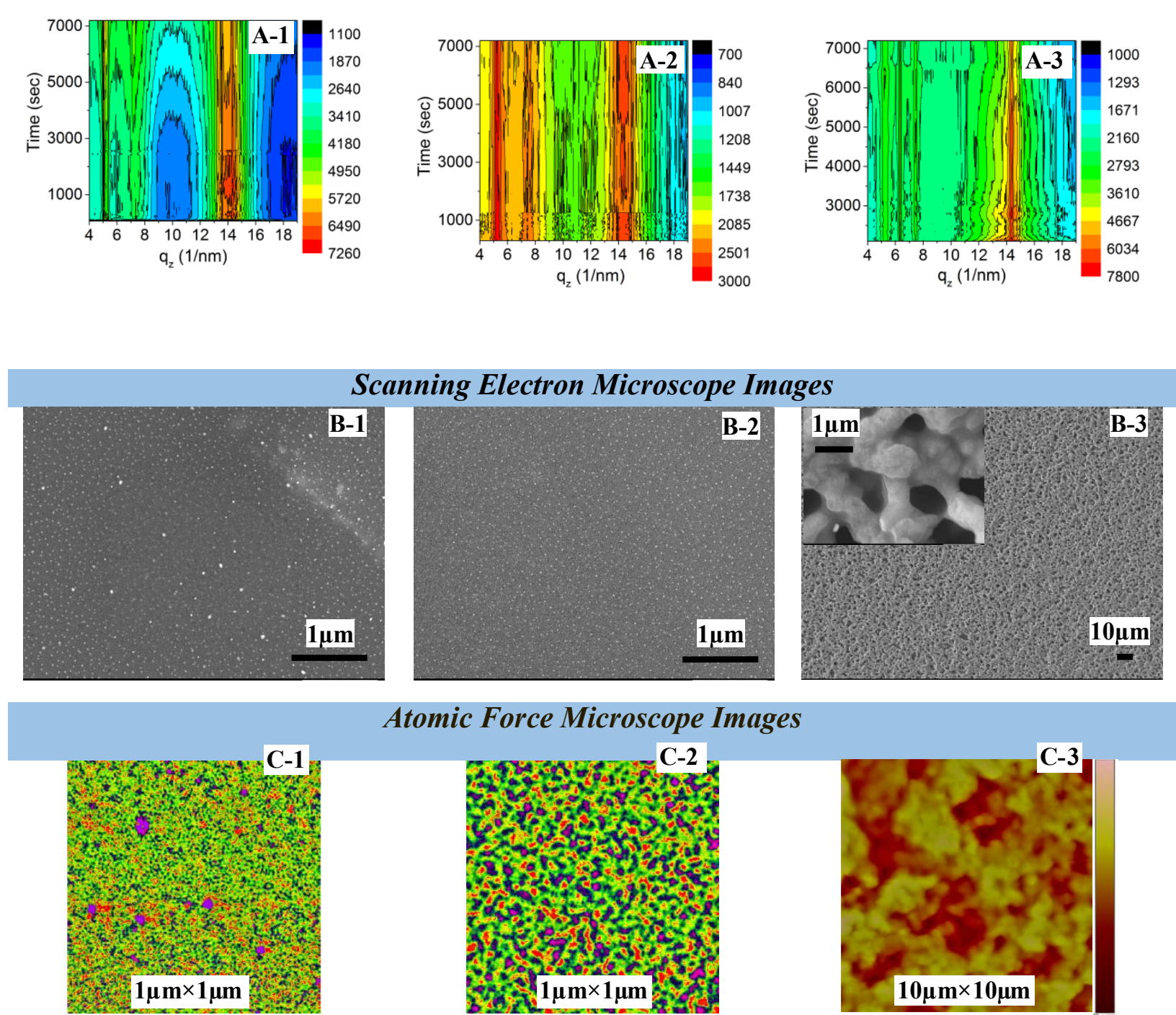

Figure 6. Out of plane cuts of the drying frames for two hours from different solvents are presented in Figures A-1 through A-3. PCBM drying frames after around two hours from different solvents. Scales of Figures B-1, B-2 and inset of B-3 is $1 \mu \mathrm{m}$ and scale of the main image of B-3 is $10 \mu \mathrm{m} . \mathrm{C}-1$ and C-2 are the AFM phase images of the films cast from chloroform and benzene, respectively. Image $\mathrm{C}-3$ is the height image with a scale of $2 \mu \mathrm{m}$

\section{IN-SITU GIWAXS OF P3HT:PCBM BLEND FILM DRYING}

The drying behavior of P3HT:PCBM blend drop cast films is rather complex compared to the individual component drying results described so far. When drop cast solutions are being dried from different solvents, we can expect that individual solubility of PCBM and P3HT in 
the solutions will play vital roles on crystallization kinetics of both components due to the fact that during the drying process phase separation of each component from the solution will be dictated by their respective solubilities. During the drying process, there is a progressive concentration of the solid phase (PCBM and P3HT) in the film as the solvent evaporates. This should ultimately lead to phase separation, wherein formation of PCBM-rich and P3HT-rich co-existing phases should occur, that further enrich with time as more solvent evaporates. These results are typical of classic phase separation phenomena. Within the PCBM rich-phase, the PCBM can undergo aggregation and crystal formation that is kinetically controlled, and likewise, within the P3HT rich phase, there should be diffusion controlled P3HT crystallization dynamics. ${ }^{40}$ In such a situation, de-mixing and aggregation of PCBM may further be enhanced due to what is known as the "depletion-aggregation" phenomena, wherein nanoparticles undergo aggregation in the presence of a (P3HT) polymer. The solution based P3HT should migrate to stable crystal nucleating site and get incorporated into the P3HT crystal growth front.

The situation is infact potentially even more complex, if the PCBM nanparticles undergo adsorption at the substrate interface while the above described aggregation and phase separation phenomena is occurring simultaneously. As such, phase separation drives wetting layer formation in blend films, so this can re-enforce the wetting kinetics of the adsorbate (PCBM) phase. In fact, the rapid drying rate of PCBM only films for all casting solvents in Figure 1 is consistent with this PCBM adsorption picture. In this regard, surface energies of the components relative to each other and the substrate is also important. Surface energies of P3HT, PCBM and silicon are $27 \mathrm{~mJ} / \mathrm{m}^{2}, 38 \mathrm{~mJ} / \mathrm{m}^{2}$ and $70 \mathrm{~mJ} / \mathrm{m}^{2}$, respectively. ${ }^{49}$ Therefore, relatively higher surface energy PCBM (as compared to that of P3HT) has a tendency of depositing at the substrate interface while P3HT wets the air interface. ${ }^{27}$

In case of films drying from chloroform, since both P3HT and PCBM have good solubility in this solvent, during the drying process PCBM can first deposit on the substrate because of higher surface energy of PCBM. In this particular case, P3HT and PCBM phase separation during the drying process may not be that prominent because of fast drying kinetics of the blend. We observe from Figure 7A-1 that the (100) and (200) peaks from P3HT appear, and PCBM forms an amorphous halo at $q_{z} \sim 14.4 \mathrm{~nm}^{-1}$ after the decreasing drying rate period. In the AFM and SEM images we observe several small PCBM aggregates that are not necessarily crystalline in nature. We utilized image $J$ to calculate the sizes of such particles. In this analysis we excluded the particles at the edge and the particles that have a circularity less than 0.8. (This is because in this calculation we did not want include particles that have partial images and which appeared to be aggregates of only two particles.) For an area of $4.8 \mu \mathrm{m} \times$ $3.6 \mu \mathrm{m}$, the number of aggregates and average aggregate diameter are 1389 and $32.4 \mathrm{~nm}$ (standard deviation $5.1 \mathrm{~nm}$ ), respectively. Particles taken into account in the calculation are presented in the Figure S9. AFM image of crystalline structure of PCBM, evolved during oven annealing at $150^{\circ} \mathrm{C}$ for $2 \mathrm{~h}$ from a $150 \mathrm{~nm}$ thin $1: 1$ ratio $\mathrm{P} 3 \mathrm{HT}: \mathrm{PCBM}$ film is presented as a right side inset of Figure 7A-3 for comparison. P3HT crystal orientation information can be derived from azimuthal integral average around the (100) peak. From the time sequential azimuthal averaging curve presented in Figure 7A-2 we observe that the crystal is oriented primarily in the edge-on direction, consistent with results on P3HT only film drying orientation orientation predominance presented earlier.

In benzene by contrast, P3HT is sparingly soluble while it is a good solvent for PCBM. Under such quiescent drying situation even though PCBM has higher surface energy as 
compared to that of $\mathrm{P} 3 \mathrm{HT}$, during the drying process, $\mathrm{P} 3 \mathrm{HT}$ precipitates out first and get deposited on the surface and eventually crystallizes during the drying process while PCBM remains in the solution and subsequently get deposited on low surface energy P3HT already deposited substrate. In this case we observe (100), (200) and (300) peaks of P3HT.
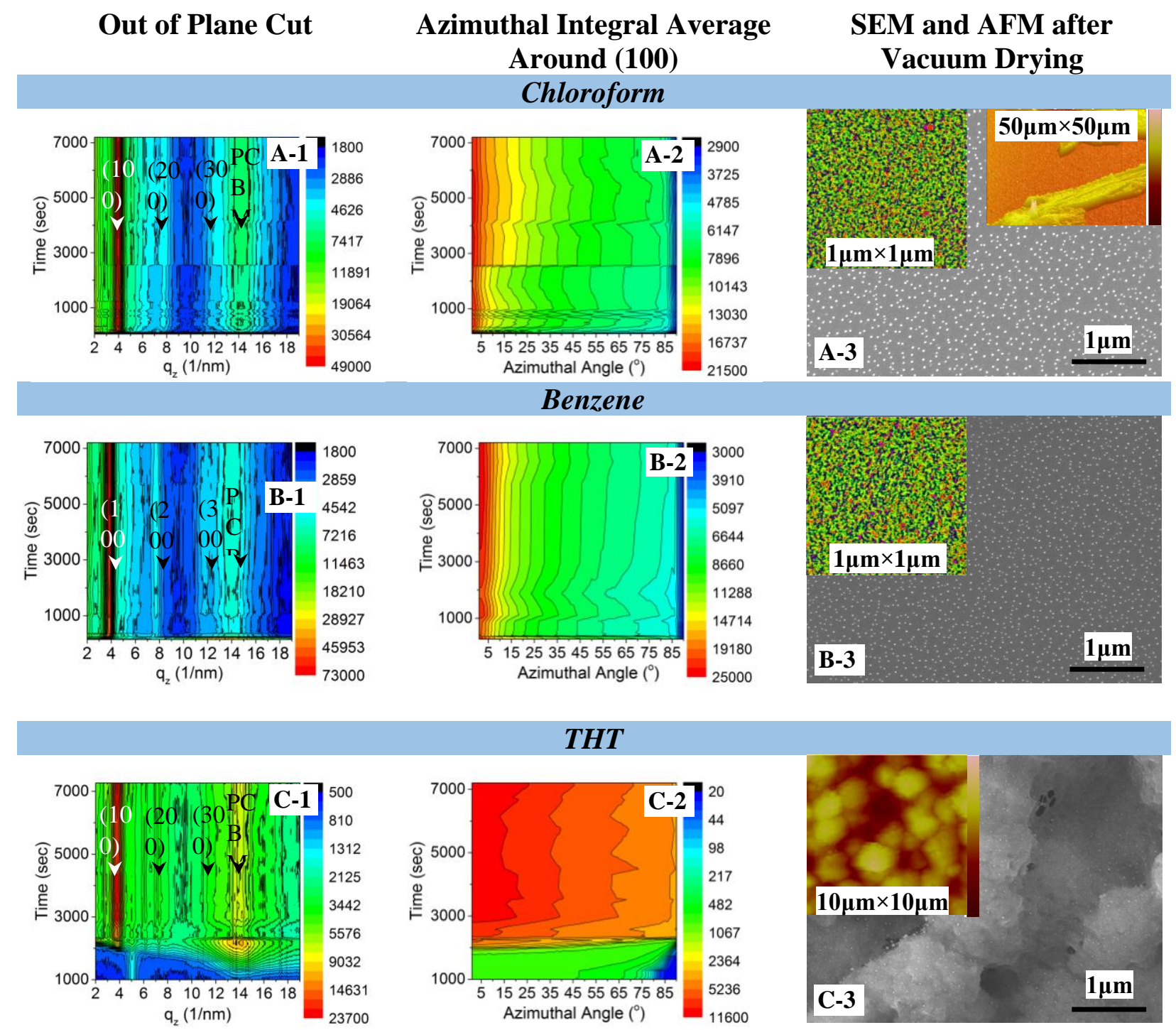

Figure 7. 1:1 ratio P3HT:PCBM blend solution drying frames for $\sim 2 \mathrm{~h}$ from different solvents. The images in the right column are SEM images with AFM images insets of the samples dried for two hours in ambient condition followed by three hours of vacuum drying. SEM scales are $1 \mu \mathrm{m}$. Results in $1^{\text {st }}$ (A-1 to $\mathrm{A}-3), 2^{\text {nd }}$ (B-1 to B-3) and $3^{\text {rd }}$ (C-1 to C-3) rows from top are for films cast from chloroform, benzene, and THT, respectively. Left inset AFM images of A-3 and B-3 are phase images and of C-3 is height images (Height scale $1 \mu \mathrm{m}$ ). Right side AFM inset of A-3 illustrates PCBM crystal structure is a $40^{\circ}$ tilted height image of an oven annealed P3HT:PCBM thin film for comparison (Height scales are $1 \mu \mathrm{m}$ ).

On the other hand a low surface energy P3HT layer deposited on the substrate is not conducive for PCBM crystal growth. ${ }^{27}$ Therefore, like the film cast from chloroform, we 
observe a PCBM halo at around the $14.4 \mathrm{~nm}^{-1} q_{z}$ value in this case (see Figure 7B-1). From the AFM image we observe smaller PCBM aggregate blobs as compared to those formed in chloroform cast film. For the benzene cast film, from SEM images of same size as that of the chloroform cast film, the number of aggregates and average aggregate diameter as determined by image $J$ analysis, are 2076 and $23.4 \mathrm{~nm}$ (standard deviation 3.4), respectively.

In case of the THT cast P3HT:PCBM film, the morphology is significantly different from chloroform and benzene cast films. In case of THT as solvent evaporates, we expect that PCBM with low solubility will precipitate first on the substrate interface and form aggregates or crystallize with random direction. It is worth reminding here that even after $2 \mathrm{~h}$ of drying under ambient condition this particular film contains $12.2 \%$ residual solvent. GIWAXS image as shown in Figure 7C-1 shows a peak at around $q_{z} \sim 14.4 \mathrm{~nm}^{-1}$, which is a superposed scattering arising from the residual solvent as well as PCBM. The sharp line in this halo arises from the random crystallites of PCBM, which also indicates that in this case PCBM is more crystalline than when cast from chloroform and benzene. For this particular THT solvent, the constant drying rate and decreasing rate ends after approximately $31 \mathrm{~min}$. However, since the sharp line in the halo first appears after about $45 \mathrm{~min}$., we conclude that the PCBM is sufficiently mobile even after the decreasing drying rate period and slowly reorganizes to form crystals. Aggregated deposition of PCBM on the substrate increases the roughness of the substrate on which P3HT subsequently gets deposited and crystallizes in this case. Molecular mobility $^{50-53}$ of P3HT in this case is largely affected by the interaction of the polymer and the PCBM roughened substrate, which in turn affects the crystallization kinetics of the P3HT polymer. Therefore the modified substrate plays a vital role in the polymer crystallization behavior of such thin films. ${ }^{54-56}$ The PCBM modified substrate for P3HT deposition and crystallization, is rough as compared to the UVO treated silicon. Edge-on to face-on crystal ratio in the final films, cast from different solvents are similar in this case (see Figure S8). Both SEM and AFM images indicates that the film roughness of the THT cast film is much higher than the other two films cast from chloroform and benzene. The rms roughness of the THT cast film is $254 \mathrm{~nm}$. Its large value arises from the fact that PCBM is first deposited on the surface of the substrate and forms randomly oriented crystals during the drying process due to its poor solubility in THT and higher surface energy compared to that of P3HT. In this case we observe the PCBM peak at $7.5 \mathrm{~nm}^{-1}$ with FWHM of $0.31 \mathrm{~nm}^{-1}$ at the end of drying cycle. Under similar conditions, such a peak did not appear for the films cast from chloroform and benzene, indicating the predominantly amorphous nature of PCBM present in these films. If we compare this finding with pure PCBM, we observe that due to presence of $\mathrm{P} 3 \mathrm{HT}$, the crystallization of PCBM is impeded. The hindrance of PCBM diffusion by P3HT to form stable nucleating site can result in such an amorphous PCBM structure.

The first P3HT crystals, denoted by the appearance of the (100) peak in such a film is slower than that of pure P3HT solutions when the casting solvent is chloroform and benzene (see Figure S8). Thus conversely, diffusion dynamics of P3HT to the growth front of P3HT is impeded due to the presence of PCBM. However, when the solvent is THT, since it is assumed that PCBM phase-separates out first during the drying process, the appearance of initial P3HT crystals is not retarded and there is no substantial difference in time of initial P3HT crystal formation from that in pure P3HT solution versus mixed P3HT:PCBM solution. Additionally, as in the pure $\mathrm{P} 3 \mathrm{HT}$ solution cast films, the edge-on to face-on ratio increases as the film dries. 
However, in this case at the end of drying cycle, the edge-on to face-on ratio is lower than that of the films from pure P3HT films. This indicates that PCBM disrupts the orientation of P3HT making it more random.

\section{SOLVENT DEPENDENCE OF P3HT CRYSTALLITES: GIWAXS PEAK-WIDTH AND d-SPACING EVOLUTION}

The sharpness of GIWAXS scattering peaks contains information on the quality, structure and dimensions of the crystalline structure. We calculate full width half max (FWHM) of (100) peaks of the GIWAXS results by fitting to a Voigt function. Changes in full width half max can be due to change in crystallite size and/or paracrystalline ordering. ${ }^{23,57}$ Separation of contributions of domain size and paracrystalline ordering requires detailed and careful analysis of the X-ray scattering results ${ }^{5,59}$ Often P3HT crystal size is determined by the Scherrer equation which was originally derived for monodisperse cubic crystallites subjected to perfectly parallel, infinitely narrow and monochromatic X-ray beam. ${ }^{23,29,40,57,60}$

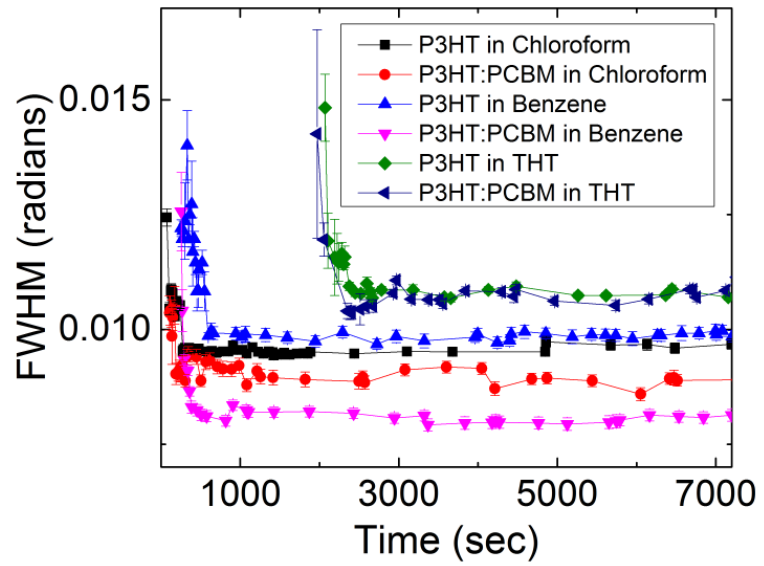

(a)

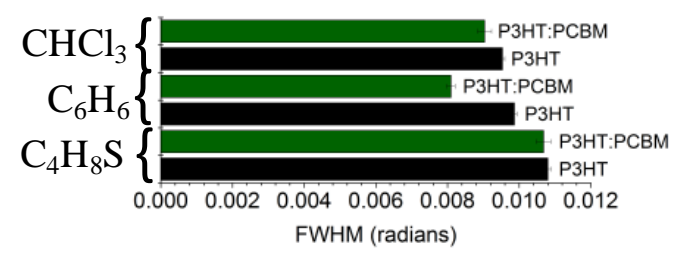

(c)

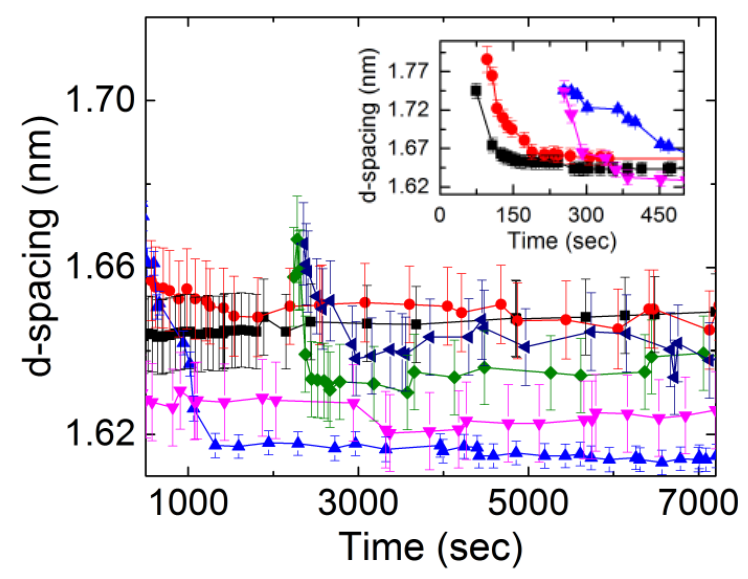

(b)

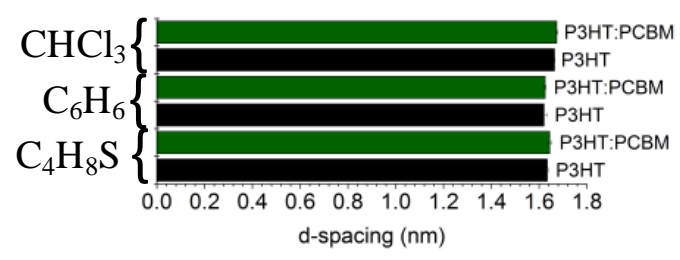

(d)

Figure 8. Variation of (a) full width half max (FWHM) of (100) P3HT peak and (b) d-spacing during the drying process of the drop cast films. Asymptotic values of FWHM and d-spacing are presented in (c) and (d). 
Blend films cast from chloroform and benzene have the lowest values of FWHM for P3HT peaks. This can imply the fact that in presence of PCBM there is an impediment to P3HT diffusion and only a few locations can form stable nucleation sites that grow over time with incorporation of surrounding amorphous P3HT. Inception of P3HT crystal growth is retarded when the casting solvent is THT due to primarily lower volatility of THT as compared to those of chloroform and benzene. The second reason for retarded P3HT crystal growth is due to higher solubility of P3HT in THT, consistent with the higher values of FWHM from THT cast films. In this case PCBM is poorly soluble in THT and therefore precipitates out of the solution at first, forming aggregates at the substrate interface. This makes the subsequent P3HT crystallization orientation more random (also see Figure 7C-2). Consequently, one may expect smaller crystal size. Asymptotic values of FWHM of GIWAXS of films cast from different solvents are presented in Figure 8(c). The d-spacing corresponds to the P3HT lattice constant in the $\boldsymbol{a}$ direction. ${ }^{61}$ When films are cast from chloroform, the d-spacings fall sharply within 2 minutes. This is due to fast evaporation of solvents, present within the inter-spaces between consecutive P3HT stacks. Similarly, d-spacing of films, cast from benzene, reduces dramatically within first few minutes. We observe that the plateau d-spacing value is higher when the solvent is chloroform as compared to benzene. This can be due to coiling of aliphatic side chain in aromatic benzene solution and its extension in aliphatic chloroform solution. We observe an intermediate plateaue d-spacing values for films cast from THT. This may be due to higher residual solvent content after drying. However, we observe that after the sharp fall in $d-$ spacing, it remains more or less constant, which we term as asymptotic d-spacing values. From Figure $8(d)$ it is observed that such asymptotic d-spacing values for all the samples are similar.

\section{CONCLUSIONS}

The in-situ film drying properties of a common OPV bulk heterojunction was investigated in detail, with respect to drying of casting solvent induced crystallization, aggregation, phase separation, substrate segregation and residual solvent. Specifically, the crystal growth kinetics of drop cast films of P3HT:PCBM solution was studied in detail, in relation to that of its individual blend components of P3HT and PCBM, cast from same set of three solvents. In-situ GIWAXS results of crystal structure evolution in these thin film systems, in conjugation with SEM and AFM was used to study the effect of different film casting solvent properties on the transient and long-term morphology of drop cast films. We observe that the competition between fullerene aggregation and crystallization and P3HT diffusion to its nucleated crystallization front largely depend on the casting solvent characteristics. Individual casting solvent studies show that P3HT crystal orientation is largely affected by the casting solvent choice, while relative solubilities of the constituent P3HT and PCBM in part determines the crystal size. Crystal formation retardation time and change in d-spacing with time is largely dependent on the volatilities of the solvents. However, asymptotic values of d-spacing of films, cast from different solvents, are quite similar. We anticipate the in-situ experimental approach presented, enabling studies of drop cast solution drying and time dependent contour representation of a BHJ system in detail will enable us to better understand and control factors impacting film morphology for different electronic applications. 


\section{Acknowledgements}

This work was funded by Department of Energy, Basic Energy Sciences via grant DEFG02-10ER4779. CHESS at Cornell University is supported by the NSF \& NIH/NIGMS via NSF award DMR-1332208. Abul F Huq would like to thank Detlef Smilgies, staff scientist at the Cornell High Energy Synchrotron Source (CHESS), NY for guidance during GIWAXS studies, and Jose Chapa, former graduate student of the University of Akron for assistance with Matlab. The authors also extend their sincere appreciation to the Deanship of Scientific Research at King Saud University for its funding of the Prolific Research Group (PRG-1436-14).

\section{Supporting Information:}

S1 "R" statistical programming code

S2 "Matlab" image processing code

S3 GIWAXS of a spin cast film

S4 Optical images of different drop cast films

S5 Drying time (sec) of different films cast from THT, benzene and chloroform

S6 Thermal gravimetric analysis (TGA) on dried films

S7 Residual solvent contents after drying cycleS8 GIWAXS images when the first P3HT crystals appear during the drying process and at the end of drying

S9 Particle size analysis on P3HT:PCBM films

S10 Top surface RMS roughness of the films 


\section{REFERENCES}

(1) Yamamoto, K.; Ochiai, S.; Wang, X.; Uchida, Y.; Kojima, K.; Ohashi, A.; Mizutani, T. Evaluation of Molecular Orientation and Alignment of poly(3-Hexylthiophene) on $\mathrm{Au}$ (111) and on poly(4-Vinylphenol) Surfaces. Thin Solid Films 2008, 516, 2695-2699.

(2) Mas-Torrent, M.; Boer, D. Den; Durkut, M.; Hadley, P.; Schenning, A. P. H. J. Field Effect Transistors Based on poly(3-Hexylthiophene) at Different Length Scales.

Nanotechnology 2004, 15, S265-S269.

(3) Surin, M.; Leclère, P.; Lazzaroni, R.; Yuen, J. D.; Wang, G.; Moses, D.; Heeger, A. J.; Cho, S.; Lee, K. Relationship between the Microscopic Morphology and the Charge Transport Properties in poly(3-Hexylthiophene) Field-Effect Transistors. J. Appl. Phys. 2006, 100, 033712-1-6.

(4) Yang, H.; Shin, T. J.; Yang, L.; Cho, K.; Ryu, C. Y.; Bao, Z. Effect of Mesoscale Crystalline Structure on the Field-Effect Mobility of Regioregular Poly(3-Hexyl Thiophene) in Thin-Film Transistors. Adv. Funct. Mater. 2005, 15, 671-676.

Chen, E.-C.; Chang, C.-Y.; Shieh, J.-T.; Tseng, S.-R.; Meng, H.-F.; Hsu, C.-S.; Horng, S.F. Polymer Photodetector with Voltage-Adjustable Photocurrent Spectrum. Appl. Phys. Lett. 2010, 96, 043507.

(6) Stathopoulos, N. A.; Palilis, L. C.; Vasilopoulou, M.; Botsialas, A.; Falaras, P.; Argitis, P. All-Organic Optocouplers Based on Polymer Light-Emitting Diodes and Photodetectors. Phys. Status Solidi 2008, 205, 2522-2525.

(7) Dang, M. T.; Hirsch, L.; Wantz, G. P3HT:PCBM, Best Seller in Polymer Photovoltaic Research. Adv. Mater. 2011, 23, 3597-3602.

(8) Tang, H.; Lu, G.; Li, L.; Li, J.; Wang, Y.; Yang, X. Precise Construction of PCBM Aggregates for Polymer Solar Cells via Multi-Step Controlled Solvent Vapor Annealing. J. Mater. Chem. 2010, 20, 683.

(9) Dang, M. T.; Wantz, G.; Bejbouji, H.; Urien, M.; Dautel, O. J.; Vignau, L.; Hirsch, L. Polymeric Solar Cells Based on P3HT:PCBM: Role of the Casting Solvent. Sol. Energy Mater. Sol. Cells 2011, 95, 3408-3418.

(10) Yang, X.; van Duren, J. K. J.; Janssen, R. A. J.; Michels, M. A. J.; Loos, J. Morphology and Thermal Stability of the Active Layer in Poly(p-phenylenevinylene)/Methanofullerene Plastic Photovoltaic Devices. Macromolecules 2004, 37, 2151-2158.

(11) Mauer, R.; Kastler, M.; Laquai, F. The Impact of Polymer Regioregularity on Charge Transport and Efficiency of P3HT:PCBM Photovoltaic Devices. Adv. Funct. Mater. 2010, 20, 2085-2092.

(12) Kim, Y.; Cook, S.; Tuladhar, S. M.; Choulis, S. a.; Nelson, J.; Durrant, J. R.; Bradley, D. D. C.; Giles, M.; McCulloch, I.; Ha, C.-S.; et al. A Strong Regioregularity Effect in SelfOrganizing Conjugated Polymer Films and High-Efficiency Polythiophene:fullerene Solar Cells. Nat. Mater. 2006, 5, 197-203.

(13) Koppe, M.; Brabec, C. J.; Heiml, S.; Schausberger, A.; Duffy, W.; Heeney, M.; McCulloch, I. Influence of Molecular Weight Distribution on the Gelation of P3HT and Its Impact on the Photovoltaic Performance. Macromolecules 2009, 42, 4661-4666.

(14) Kim, Y. S.; Lee, Y.; Lee, W.; Park, H.; Han, S.-H.; Lee, S.-H. Effects of Molecular Weight and Polydispersity of poly(3-Hexylthiophene) in Bulk Heterojunction Polymer Solar Cells. Curr. Appl. Phys. 2010, 10, 329-332.

(15) Nam, Y. M.; Huh, J.; Jo, W. H. Optimization of Thickness and Morphology of Active Layer for High Performance of Bulk-Heterojunction Organic Solar Cells. Sol. Energy 
Mater. Sol. Cells 2010, 94, 1118-1124.

(16) Bulliard, X.; Ihn, S.-G.; Yun, S.; Kim, Y.; Choi, D.; Choi, J.-Y.; Kim, M.; Sim, M.; Park, J.-H.; Choi, W.; et al. Enhanced Performance in Polymer Solar Cells by Surface Energy Control. Adv. Funct. Mater. 2010, 20, 4381-4387.

(17) Zhang, F.; Jespersen, K. G.; Björström, C.; Svensson, M.; Andersson, M. R.; Sundström, V.; Magnusson, K.; Moons, E.; Yartsev, a.; Inganäs, O. Influence of Solvent Mixing on the Morphology and Performance of Solar Cells Based on Polyfluorene Copolymer/Fullerene Blends. Adv. Funct. Mater. 2006, 16, 667-674.

(18) Peet, J.; Kim, J. Y.; Coates, N. E.; Ma, W. L.; Moses, D.; Heeger, A. J.; Bazan, G. C. Efficiency Enhancement in Low-Bandgap Polymer Solar Cells by Processing with Alkane Dithiols. Nat. Mater. 2007, 6, 497-500.

(19) Al-Ibrahim, M.; Ambacher, O.; Sensfuss, S.; Gobsch, G. Effects of Solvent and Annealing on the Improved Performance of Solar Cells Based on poly(3-Hexylthiophene): Fullerene. Appl. Phys. Lett. 2005, 86, 201120-201121-2.

(20) Kim, Y.; Choulis, S. A.; Nelson, J.; Bradley, D. D. C.; Cook, S.; Durrant, J. R. Device Annealing Effect in Organic Solar Cells with Blends of Regioregular poly(3Hexylthiophene) and Soluble Fullerene. Appl. Phys. Lett. 2005, 86, 063502-1 - 3. Liu, H.-J.; Jeng, U.-S.; Yamada, N. L.; Su, A.-C.; Wu, W.-R.; Lin, C.-J.; Wei, K.-H.; Chiu, M.-Y. Surface and Interface Porosity of Polymer / Fullerene-Derivative Thin Films Revealed by Contrast Variation of Neutron and X-Ray Reflectivity. Soft Matter 2011, 7, 9276-9282.

(22) Müller-Buschbaum, P. The Active Layer Morphology of Organic Solar Cells Probed with Grazing Incidence Scattering Techniques. Adv. Mater. 2014, 26, 7692-7709.

(23) Salleo, B. A.; Kline, R. J.; Delongchamp, D. M.; Chabinyc, M. L. Microstructural Characterization and Charge Transport in Thin Films of Conjugated Polymers. Adv. Mater. 2010, 22, 3812-3838.

(24) Germack, D. S.; Chan, C. K.; Kline, R. J.; Fischer, D. a.; Gundlach, D. J.; Toney, M. F.; Richter, L. J.; DeLongchamp, D. M. Interfacial Segregation in Polymer/fullerene Blend Films for Photovoltaic Devices. Macromolecules 2010, 43, 3828-3836.

(25) Jung, Y.; Kline, R. J.; Fischer, D. a.; Lin, E. K.; Heeney, M.; McCulloch, I.; DeLongchamp, D. M. The Effect of Interfacial Roughness on the Thin Film Morphology and Charge Transport of High-Performance Polythiophenes. Adv. Funct. Mater. 2008, 18, $742-750$.

(26) Kline, R. J.; DeLongchamp, D. M.; Fischer, D. a.; Lin, E. K.; Heeney, M.; McCulloch, I.; Toney, M. F. Significant Dependence of Morphology and Charge Carrier Mobility on Substrate Surface Chemistry in High Performance Polythiophene Semiconductor Films. Appl. Phys. Lett. 2007, 90, 062117.

(27) He, C.; Germack, D. S.; Kline, R. J.; Delongchamp, D. M.; Fischer, D. A.; Snyder, C. R.; Toney, M. F.; Kushmerick, J. G.; Richter, L. J. Influence of Substrate on Crystallization in Polythiophene/fullerene Blends. Sol. Energy Mater. Sol. Cells 2011, 95, 1375-1381.

(28) DeLongchamp, D. M.; Kline, R. J.; Lin, E. K.; Fischer, D. a.; Richter, L. J.; Lucas, L. a.; Heeney, M.; McCulloch, I.; Northrup, J. E. High Carrier Mobility Polythiophene Thin Films: Structure Determination by Experiment and Theory. Adv. Mater. 2007, 19, 833837.

(29) Chou, K. W.; Yan, B.; Li, R.; Li, E. Q.; Zhao, K.; Anjum, D. H.; Alvarez, S.; Gassaway, R.; Biocca, A.; Thoroddsen, S. T.; et al. Spin-Cast Bulk Heterojunction Solar Cells: A 
Dynamical Investigation. Adv. Mater. 2013, 25, 1923-1929.

(30) Richter, L. J.; DeLongchamp, D. M.; Bokel, F. A.; Engmann, S.; Chou, K. W.; Amassian, A.; Schaible, E.; Hexemer, A. In Situ Morphology Studies of the Mechanism for Solution Additive Effects on the Formation of Bulk Heterojunction Films. Adv. Energy Mater. 2015, 5, 1-11.

(31) Roth, S. V; Herzog, G.; Körstgens, A.; Buffet, A.; Schwartzkopf, M.; Perlich, J.; Kashem, M. M. A.; Döhrmann, R.; Gehrke, R.; Rothkirch, A.; et al. In Situ Observation of Cluster Formation during Nanoparticle Solution Casting on a Colloidal Film. J. Phys. Condens. Matter 2011, 23, 254208.

(32) Grodd, L.; Pietsch, U.; Grigorian, S. Direct Correlation Between Electric and Structural Properties During Solidifi Cation of Poly(3-Hexylthiophene) Drop-Cast Films. Macromol. Rapid Commun. 2012, 33, 1765-1769.

(33) Verploegen, E.; Miller, C. E.; Schmidt, K.; Bao, Z.; Toney, M. F. Manipulating the Morphology of P3HT-PCBM Bulk Heterojunction Blends with Solvent Vapor Annealing. Chem. Mater. 2012, 24, 3923-3931.

(34) Joung, M. J.; Kim, C. A.; Kang, S. Y.; Baek, K.-H.; Kim, G. H.; Ahn, S. D.; You, I. K.; Ahn, J. H.; Suh, K. S. The Application of Soluble and Regioregular poly(3Hexylthiophene) for Organic Thin-Film Transistors. Synth. Met. 2005, 149, 73-77.

(35) Chang, J.-F.; Sun, B.; Breiby, D. W.; Nielsen, M. M.; Sölling, T. I.; Giles, M.; McCulloch, I.; Sirringhaus, H. Enhanced Mobility of Poly(3-Hexylthiophene) Transistors by SpinCoating from High-Boiling-Point Solvents. Chem. Mater. 2004, 16, 4772-4776.

(36) Yaws, C. L.; Lin, X.; Bu, L.; Balundgi, D. R.; Tripathi, S. Chemical Properties Handbook; Yaws, C. L., Ed.; First.; McGraw-Hill: New York, 1999.

(37) Ferreiro, V.; Douglas, J. F.; Warren, J.; Karim, A. Growth Pulsations in Symmetric Dendritic Crystallization in Thin Polymer Blend Films. Phys. Rev. E 2002, 65, 051606-1 $-16$.

(38) Azzellino, G.; Grimoldi, A.; Binda, M.; Caironi, M.; Natali, D.; Sampietro, M. Fully Inkjet-Printed Organic Photodetectors with High Quantum Yield. Adv. Mater. 2013, 25, 6829-6833.

(39) Kim, H. J.; Park, J. H.; Lee, H. H.; Lee, D. R.; Kim, J.-J. The Effect of Al Electrodes on the Nanostructure of poly(3-Hexylthiophene): Fullerene Solar Cell Blends during Thermal Annealing. Org. Electron. 2009, 10, 1505-1510.

(40) Wu, W.-R.; Jeng, U.-S.; Su, C.-J.; Wei, K.-H.; Su, M.-S.; Chiu, M.-Y.; Chen, C.-Y.; Su, W.-B.; Su, C.-H.; Su, A.-C. Competition between Fullerene Crystallization upon Annealing of Bulk Heterojunction Solar Cells. ACS Nano 2011, 5, 6233-6243.

(41) Wang, S.; Kiersnowski, A.; Pisula, W.; Müllen, K. Microstructure Evolution and Device Performance in Solution-Processed Polymeric Field-Effect Transistors: The Key Role of the First Monolayer. J. Am. Chem. Soc. 2012, 134, 4015-4018.

(42) Abdellah, A.; Virdi, K. S.; Meier, R.; Döblinger, M.; Müller-buschbaum, P.; Scheu, C.; Lugli, P.; Scarpa, G. Successive Spray Deposition of P3HT/PCBM Organic Photoactive Layers : Material Composition and Device Characteristics. Adv. Funct. Mater. 2012, 22, 4078-4086.

(43) Khapli, S.; Rianasari, I.; Blanton, T.; Weston, J.; Gilardetti, R.; Neiva, R.; Tovar, N.; Coelho, P. G.; Jagannathan, R. Fabrication of Hierarchically Porous Materials and Nanowires through Co Ff Ee Ring Effect. Appl. Mater. Interfaces 2014, 6, 20643-20653. (44) Yunker, P. J.; Still, T.; Lohr, M. A.; Yodh, A. G. Suppression of the Coffee-Ring Effect 
by Shape-Dependent Capillary Interactions. Nature 2011, 476, 308-311.

(45) Machui, F.; Langner, S.; Zhu, X.; Abbott, S.; Brabec, C. J. Determination of the P3HT:PCBM Solubility Parameters via a Binary Solvent Gradient Method: Impact of Solubility on the Photovoltaic Performance. Sol. Energy Mater. Sol. Cells 2012, 100, 138146.

(46) Page, K. A.; Kusoglu, A.; Stafford, C. M.; Kim, S.; Kline, R. J.; Weber, A. Z. Confinement-Driven Increase in Ionomer Thin-Film Modulus. Nano Lett. 2014, 14, 2299 2304.

(47) Hopkinson, P. E.; Staniec, P. A.; Pearson, A. J.; Dunbar, A. D. F.; Wang, T.; Ryan, A. J.; Jones, R. A. L.; Lidzey, D. G.; Donald, A. M. A Phase Diagram of the P3HT : PCBM Organic Photovoltaic System : Implications for Device Processing and Performance. Macromolecules 2011, 44, 2908-2917.

(48) Strathmann, H.; Kock, K. The Formaion Mechanism of Phase Inversion Membranes. Desalination 1977, 21, 241-255.

(49) Kokubu, R.; Yang, Y. Vertical Phase Separation of Conjugated Polymer and Fullerene Bulk Heterojunction Films Induced by High Pressure Carbon Dioxide Treatment at Ambient Temperature. Phys. Chem. Chem. Phys. 2012, 14, 8313-8318.

(50) Zheng, X.; Rafailovich, M. H.; Sokolov, J.; Strzhemechny, Y.; Schwarz, S. A.; Sauer, B. B.; Rubinstein, M. Long-Range Effects on Polymer Diffusion Induced by a Bounding Interface. Phys. Rev. Lett. 1997, 79, 241-244.

(51) Zheng, X.; Sauer, B. B.; Van Alsten, J. G.; Schwarz, S. A.; Rafailovich, M. H.; Sokolov, J.; Rubinstein, M. Reptation Dynamics of a Polymer Melt near an Attractive Solid Interface. Phys. Rev. Lett. 1995, 74, 407-410.

(52) Russell, T. P.; Kumar, S. K. The One That Got Away. Nature 1997, 386, 771-772.

(53) Lin, E. K.; Kolb, R.; Satija, S. K.; Wu, W. Reduced Polymer Mobility near the Polymer/Solid Interface as Measured by Neutron Reflectivity. Macromolecules 1999, 32, 3753-3757.

(54) Reiter, G.; Sommer, J.-U. Crystallization of Adsorbed Polymer Monolayers. Phys. Rev. Lett. 1998, 80, 3771-3774.

(55) Despotopoulou, M. M.; Frank, C. W.; Miller, R. D.; Rabolt, J. F. Kinetics of Chain Organization in Ultrathin Poly(di-N-Hexylsilane) Films. Macromolecules 1996, 29, 57975804.

(56) Schönherr, H.; Frank, C. W. Ultrathin Films of Poly(ethylene Oxides) on Oxidized Silicon . 1 . Spectroscopic Characterization of Film Structure and Crystallization Kinetics. Macromolecules 2003, 36, 1188-1198.

(57) Ruland, W.; Smarsly, B. M. Two-Dimensional Small-Angle X-Ray Scattering of SelfAssembled Nanocomposite Films with Oriented Arrays of Spheres: Determination of Lattice Type, Preferred Orientation, Deformation and Imperfection. J. Appl. Crystallogr. 2007, 40, 409-417.

(58) Warren, B. E. X-Ray Diffraction; Courier Dover Publications: New York, 1969.

(59) Prosa, T. J.; Moulton, J.; Heeger, a. J.; Winokur, M. J. Diffraction Line-Shape Analysis of Poly(3-Dodecylthiophene): A Study of Layer Disorder through the Liquid Crystalline Polymer Transition. Macromolecules 1999, 32, 4000-4009.

(60) Holzwarth, U.; Gibson, N. The Scherrer Equation versus the "Debye-Scherrer Equation." Nat. Nanotechnol. 2011, 6, 534.

(61) Lilliu, S.; Agostinelli, T.; Pires, E.; Hampton, M.; Nelson, J.; Macdonald, J. E. Dynamics 
of Crystallization and Disorder during Annealing of P3HT/PCBM Bulk Heterojunctions. Macromolecules 2011, 44, 2725-2734. 